\title{
Optimization of the Electrochemical Performance of a Composite Polymer Electrolyte Based on $\mathrm{PVA}_{2} \mathrm{~K}_{2} \mathrm{CO}_{3}-\mathrm{SiO}_{2}$ Composite
}

\author{
Bashir Abubakar Abdulkadir ${ }^{1, *}$, John Ojur Dennis ${ }^{1}$, Yas Al-Hadeethi ${ }^{2}$, Muhammad Fadhlullah Bin Abd. Shukur ${ }^{1}$, \\ E. M. Mkawi ${ }^{2}$, Nuha Al-Harbi ${ }^{2}$, K. H. Ibnaouf ${ }^{3}$, O. Aldaghri ${ }^{3}{ }^{(1)}$, Fahad Usman ${ }^{1}{ }^{\circledR}$ and Abdullahi Abbas Adam ${ }^{1}$ (1) \\ 1 Fundamental and Applied Sciences Department, Universiti Teknologi PETRONAS, Tronoh 32610, Malaysia \\ johndennis@utp.edu.my (J.O.D.); mfadhlullah.ashukur@utp.edu.my (M.F.B.A.S.); fahatu11@gmail.com (F.U.); \\ ibneeabdullah234@gmail.com (A.A.A.) \\ 2 Department of Physics, Faculty of Science, King Abdulaziz University, Jeddah 21589, Saudi Arabia; \\ yalhadeethi@kau.edu.sa (Y.A.-H.); emrzog@kau.edu.sa (E.M.M.); nallhibi0001@stu.kau.edu.sa (N.A.-H.) \\ 3 Physics Department, College of Science, Imam Mohammad Ibn Saud Islamic University (IMSIU), \\ P.O. Box 5701, Riyadh 11432, Saudi Arabia; khiahmed@imamu.edu.sa (K.H.I.); odaghri@gmail.com (O.A.) \\ * Correspondence: abubakarbashir150@gmail.com
}

Citation: Abdulkadir, B.A.; Ojur Dennis, J.; Al-Hadeethi, Y.; Shukur, M.F.B.A.; Mkawi, E.M.; Al-Harbi, N.; Ibnaouf, K.H.; Aldaghri, O.; Usman, F.; Abbas Adam, A. Optimization of the Electrochemical Performance of a Composite Polymer Electrolyte Based on PVA- $\mathrm{K}_{2} \mathrm{CO}_{3}-\mathrm{SiO}_{2}$ Composite. Polymers 2021, 13, 92. https:// doi.org/10.3390/polym13010092

Received: 3 December 2020 Accepted: 23 December 2020 Published: 28 December 2020

Publisher's Note: MDPI stays neutral with regard to jurisdictional clai$\mathrm{ms}$ in published maps and institutional affiliations.

Copyright: (C) 2020 by the authors. Licensee MDPI, Basel, Switzerland. This article is an open access article distributed under the terms and conditions of the Creative Commons Attribution (CC BY) license (https:// creativecommons.org/licenses/by/ $4.0 /)$.

\begin{abstract}
Composite polymer electrolyte (CPE) based on polyvinyl alcohol (PVA) polymer, potassium carbonate $\left(\mathrm{K}_{2} \mathrm{CO}_{3}\right)$ salt, and silica $\left(\mathrm{SiO}_{2}\right)$ filler was investigated and optimized in this study for improved ionic conductivity and potential window for use in electrochemical devices. Various quantities of $\mathrm{SiO}_{2}$ in wt.\% were incorporated into $\mathrm{PVA}_{2} \mathrm{~K}_{2} \mathrm{CO}_{3}$ complex to prepare the CPEs. To study the effect of $\mathrm{SiO}_{2}$ on PVA- $\mathrm{K}_{2} \mathrm{CO}_{3}$ composites, the developed electrolytes were characterized for their chemical structure (FTIR), morphology (FESEM), thermal stabilities (TGA), glass transition temperature (differential scanning calorimetry (DSC)), ionic conductivity using electrochemical impedance spectroscopy (EIS), and potential window using linear sweep voltammetry (LSV). Physicochemical characterization results based on thermal and structural analysis indicated that the addition of $\mathrm{SiO}_{2}$ enhanced the amorphous region of the PVA- $\mathrm{K}_{2} \mathrm{CO}_{3}$ composites which enhanced the dissociation of the $\mathrm{K}_{2} \mathrm{CO}_{3}$ salt into $\mathrm{K}^{+}$and $\mathrm{CO}_{3}{ }^{2-}$ and thus resulting in an increase of the ionic conduction of the electrolyte. An optimum ionic conductivity of $3.25 \times 10^{-4}$ and $7.86 \times 10^{-3} \mathrm{mScm}^{-1}$ at ambient temperature and at $373.15 \mathrm{~K}$, respectively, at a potential window of $3.35 \mathrm{~V}$ was observed at a composition of $15 \mathrm{wt} . \% \mathrm{SiO}_{2}$. From FESEM micrographs, the white granules and aggregate seen on the surface of the samples confirm that $\mathrm{SiO}_{2}$ particles have been successfully dispersed into the PVA- $\mathrm{K}_{2} \mathrm{CO}_{3}$ matrix. The observed ionic conductivity increased linearly with increase in temperature confirming the electrolyte as temperature-dependent. Based on the observed performance, it can be concluded that the CPEs based on PVA- $\mathrm{K}_{2} \mathrm{CO}_{3}-\mathrm{SiO}_{2}$ composites could serve as promising candidate for portable and flexible next generation energy storage devices.
\end{abstract}

Keywords: composite polymer electrolyte; $\mathrm{K}_{2} \mathrm{CO}_{3} ; \mathrm{PVA} ; \mathrm{SiO}_{2} ;$ plasticizer

\section{Introduction}

The current trend to produce green energy and suitable energy storage is driven by the need to replace fossil fuels which have an adverse effect on the environment [1]. With increasing development in sustainable power sources from sun and wind as well as in electric and hybrid vehicles with low $\mathrm{CO}_{2}$ emanations, energy storage devices such as supercapacitors have become a major field of interest to researchers [2]. They have recently received increased attention due to their numerous advantages arising from occupying an important position in relation to specific power and specific energy compared to other energy storage devices such as capacitors, batteries, and fuel cells, and hence have the essential characteristics to satisfy the energy storage requirements of the present and the future [3]. Supercapacitors may be categorized into three types: electrode double layer 
capacitors (EDLCs), pseudocapacitors, and hybrid capacitors. All three types of supercapacitors consist of three main components namely electrode, separator, and electrolyte on which the performance of the electrochemical supercapacitors depends.

The electrolyte is a vital component providing the ionic conductivity and operating potential window of the supercapacitor [2]. Electrolytes used in supercapacitors commonly have two important functions: providing ions during charge and discharge process and preventing the electrodes from short-circuiting. Most of the earliest studies on supercapacitors mainly reported the utilization of liquid electrolytes in both laboratories and industries [4,5]. Liquid electrolytes are mostly composed of aqueous solutions of acids such as $\mathrm{H}_{2} \mathrm{SO}_{4}, \mathrm{LiSO}_{4}$, and $\mathrm{KOH}$, which allows supercapacitors to reach higher conductivity values [6]. However, the utilization of liquid electrolytes has significant limitations such as environmental unfriendliness since it may be easily leach out, low life cycle, long charging time, and low voltage window [7]. Recently, with the advances in electrolyte research coupled with serious disadvantages in using liquid electrolytes, polymer electrolytes (PE) in the form of a solid or gel have been proposed and researched $[5,8]$.

Polymer electrolytes (PE) are a promising substitute for the traditional liquid electrolytes due to their long cycle life, adaptability, high ionic conductivity, high chemical and mechanical dependability, wide potential window, sustainable, environmental friendliness, and leakage elimination possibility [9]. A polymer, salt, and filler composite could be an appropriate way to produce unique composite polymer electrolyte (CPEs) that are capable of higher electrochemical performance in energy storage devices. It has been established that when salt with low lattice energy such as $\mathrm{K}_{2} \mathrm{CO}_{3}$ is dissolved in a polymer matrix, CPEs are formed [10]. It is reported that polymers such as polyvinyl alcohol (PVA) are attractive for the synthesis of CPEs. PVA is a synthetic polymer produced through the hydrolysis of polyvinyl acetate. Vinyl ester obtained from polymers is also used with chloroacetate rather than acetate. Properties such as biocompatibility, semi-crystalline nature, environmental friendliness, non-toxicity, high solubility in water, excellent film-forming capacity, high dielectric constant, and high thermal stability $\left(200^{\circ} \mathrm{C}\right)$ make PVA prospective material for the polymer electrolytes [11]. The existence of polar group $(-\mathrm{OH})$ on the PVA support is adequate to dissolve conducting salts. PVA is a hydrophilic polymer and features a high density of reactive chemical functional groups. These functional groups are substantial for mixing with conducting salt and a filler. The utilization of PVA as substantive material as a host polymer for electrolyte was reported earlier [12].

Solid polymer electrolyte (SPE) and gel polymer electrolyte (GPE) or CPEs have shown enhanced reliability and dependability over liquid electrolytes [5]. Among the polymer electrolytes, GPEs have the advantage of wide potential window and high ionic conductivity [13]. GPEs were reported to have ionic conductivity that is very similar to that of liquid electrolytes but with diminished spillage. Normally, the polymer framework in GPE holds the liquid electrolyte consolidating the generally high conductivity of liquid electrolytes with the strong characteristics of solid electrolytes. GPEs or CPEs may be used as a thin film as both an electrolyte and a separator with low internal corrosion, simple principles and modes of construction, and flexibility in packaging. However, the shortcomings of GPEs are frail mechanical quality, which will bring about internal short circuits, and a restricted scope of working temperature [14]. To solve these shortcomings and improve the weak mechanical strength and the low ionic conductivity of GPEs or CPEs, fillers are usually added [15]. The addition of fillers is reported to be one amongst the foremost approaches to enhance the mobility of ions or/and the interfacial interaction among ions and polar groups within the electrolytes [16]. The semi-crystalline nature of the polymer in CPE also presents difficulty for ion transport [17]. One amongst the foremost favorable ways of increasing the amorphous region of the polymer and enhancing the conductivity in CPE is blending the polymer with an appropriate filler such as $\mathrm{SiO}_{2}$. Moreover, the incorporation of filler can modify the polymeric nature of the electrolyte and enhanced conductivity. The selection of filler and its concentration was reported to influence film absorptivity and mechanical properties [18]. 
$\mathrm{SiO}_{2}$ as a filler is an attractive material for preparing CPEs because it can improve electrochemical performance of the material by providing large surface area and high conductivity and promoting good electrolyte-electrode interaction. More enhancements of these properties depend on how well the silica dispersed into the CPEs. Good dispersion of $\mathrm{SiO}_{2}$ particles often leads to morphology suitable for the enhancement of electrochemical performance. Secondly, addition of hydrophilic fumed silica with silanol $(\mathrm{Si}-\mathrm{OH})$ groups on its surface makes the diameter of an electrolyte much better [17]. Furthermore, $\mathrm{SiO}_{2}$ as a filler was reported to serve as a supporter to stand tunneling structures and to hold the liquid electrolyte. It also improves ionic conductivity of the composites by reducing the crystallinity of the polymer and introducing Lewis acid-base interactions between the polar surface groups of the inorganic filler and the electrolyte ionic species. In addition, $\mathrm{SiO}_{2}$ increases mechanical properties of the electrolytes and expands the cation transference number and interfacial stability between the electrolyte-electrode interfaces [18].

The addition of silica into the electrolyte was found to reduce glass transition temperature $\left(T_{g}\right)$ and melting temperature $\left(T_{m}\right)$ of the CPEs, which could be due to the interaction between the added silica and cation that leads to the increase in the ionic conductivities [17]. Shekibi and co-workers [19] reported that addition of silica powders into PEs has two benefits. The first benefit is to improve the conductivity, which is verified by experiments. The mechanism is that addition of silica particles will prevent the process of polymer crystallization at low temperatures so that the amorphous region in charge of ionic conductivity is preserved. Another benefit is that the stability of the interface between the electrolytes and the electrodes can be improved with the addition of silica particles. Polymer electrolytes with ceramic fillers, salts, ionic liquids, and other plasticizers are widely reported recently [17-22]. However, the study of silica $\left(\mathrm{SiO}_{2}\right)$ as a filler in a polymer-salt composite of PVA- $\mathrm{K}_{2} \mathrm{CO}_{3}$ is yet to be reported. Therefore, the effects of $\mathrm{SiO}_{2}$ particles on the electrochemical properties of CPEs based on PVA- $\mathrm{K}_{2} \mathrm{CO}_{3}$ composites were investigated and are reported herein.

The objective of the present work is to report the preparation and characterization of CPEs based on PVA- $\mathrm{K}_{2} \mathrm{CO}_{3}$ composite with varying amounts of $\mathrm{SiO}_{2}$ as filler. The study includes optimization of the amount of $\mathrm{SiO}_{2}$ in PVA- $\mathrm{K}_{2} \mathrm{CO}_{3}$ composite for improved ionic conductivity and potential window. The various samples of CPEs of PVA- $\mathrm{K}_{2} \mathrm{CO}_{3}$ composite with varying amounts of $\mathrm{SiO}_{2}$ are evaluated using FTIR, FESEM, TGA, differential scanning calorimetry (DSC), electrochemical impedance spectroscopy (EIS), and linear sweep voltammetry (LSV) for their functional groups, morphology, thermal stability, $T_{g}$, ionic conductivity, and potential window, respectively.

\section{Materials and Methods}

\subsection{Material}

PVA (hydrolyzed 99\%), silica, and potassium carbonate (anhydrous) were obtained from Sigma-Aldrich (002008792-H) supplied by Avantis chemicals supply (Ipoh-Perak, Malaysia). All the chemicals were of analytical grade and used as received. For all the experiments' preparation, deionized water was used.

\subsection{Preparation of $\mathrm{CPE}$ Based on $\mathrm{PVA}-\mathrm{K}_{2} \mathrm{CO}_{3}-\mathrm{SiO}_{2}$ Composite}

PVA as host polymer, potassium carbonate $\left(\mathrm{K}_{2} \mathrm{CO}_{3}\right)$ as salt, and silica $\left(\mathrm{SiO}_{2}\right)$ as filler were used to prepare the CPEs. The electrolytes were prepared with the dissolution technique with varying amounts (ratios) of the filler. For the preparation of the non-filler CPEs, a fixed ratio of PVA and $\mathrm{K}_{2} \mathrm{CO}_{3}$ (70:30) was added into $20 \mathrm{~mL}$ of deionized water in a glass beaker. The two solutions were mixed and heated at $80^{\circ} \mathrm{C}$ with continuous vigorous stirring using thermostat until the two solutions were completely dissolved to form a composite of PVA- $\mathrm{K}_{2} \mathrm{CO}_{3}$ as reported in our previous study [23]. For the preparation of CPEs containing filler, an appropriate amount of $\mathrm{SiO}_{2}$ was added to the prepared PVA$\mathrm{K}_{2} \mathrm{CO}_{3}$ composites, heated at $80^{\circ} \mathrm{C}$ continuously with vigorous stirring until homogeneous, clear, and viscous solution were obtained. The optimization study was conducted by 
varying the amount $\mathrm{SiO}_{2}$ while keeping the polymer-salt ratio constant as shown in Table 1. The resulting polymer electrolytes were coded as PKS0, PKS5, PKS10, PKS15, PKS20, and PKS25 for electrolyte incorporated with $0,5,10,15,20$, and $25 \mathrm{wt} . \%$ of $\mathrm{SiO}_{2}$, respectively. All the samples were stored in a desiccator prior to analysis and testing.

Table 1. Designation and composition of the synthesized composite polymer electrolytes (CPEs).

\begin{tabular}{cc}
\hline Designation & $\mathbf{S i O}_{\mathbf{2}}$ Composition (wt.\%) \\
\hline PKS0 & 0 \\
PKS5 & 15 \\
PKS10 & 10 \\
PKS15 & 15 \\
PKS20 & 20 \\
PKS25 & 25 \\
\hline
\end{tabular}

The synthesized CPEs, a typical one shown in Figure 1, were observed to be homogenous, clear, and viscous.

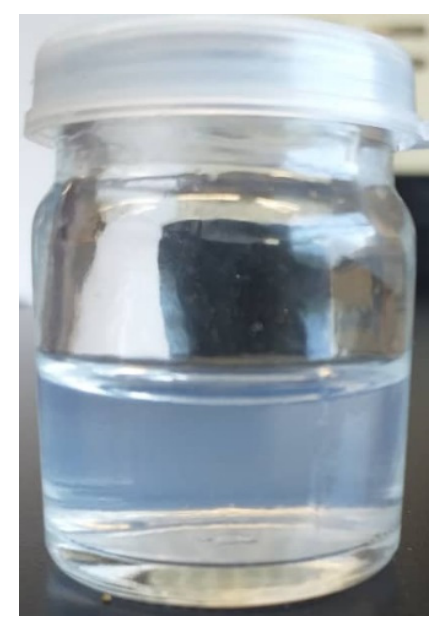

Figure 1. The view of plasticized composite electrolyte based on polyvinyl alcohol-potassium carbonate-silica (PVA- $\left.\mathrm{K}_{2} \mathrm{CO}_{3}-\mathrm{SiO}_{2}\right)$.

\subsection{Physicochemical Characterization}

Fourier transform infrared (FTIR) analysis was conducted on an FTIR spectrometer (Bruker Instruments, model Aquinox 55, Oberkochen, Germany) in the $4000-400 \mathrm{~cm}^{-1}$ range using $\mathrm{KBr}$ pellets with the scanning resolution of $4 \mathrm{~cm}^{-1}$. The morphology of the synthesized samples was examined using field-emission scanning electron microscopy (model: Zeiss Supra 55VP, Oberkochen, Germany) at $20 \mathrm{kV}$. Before the testing, the samples were vacuum dried for a period of $10 \mathrm{~min}$ on a carbon tape attached to an aluminum stub. The samples were coated with gold $(\mathrm{Au})$ film in an evaporator to avoid charging and were then scanned at a magnification of $20 \mathrm{k}$ and at an operation voltage of $30 \mathrm{kV}$ [23].

The thermal stabilities of the as prepared CPEs were evaluated using thermogravimetric analyzer (TGA), model SHIMADZU DTG-60/60H (Kyoto, Japan). About $3 \mathrm{mg}$ of the samples were heated at a heating rate of $10^{\circ} \mathrm{C} / \mathrm{min}$ in $\mathrm{N}_{2}$ atmosphere from room temperature to $900{ }^{\circ} \mathrm{C}$ and the weight of the sample was measured as a function of the temperature. Differential scanning calorimetry (DSC) (Model DSC Q2000 V24.11, Oberkochen, Germany) was used to examine thermal properties of the samples. The glass transition temperature $\left(T_{g}\right)$ of the samples were recorded at a heating scan rate of $10^{\circ} \mathrm{C} / \mathrm{m}$ in from $50{ }^{\circ} \mathrm{C}$ to $400{ }^{\circ} \mathrm{C}$ under $\mathrm{N}_{2}$ atmosphere. A sample weight of about $4 \mathrm{mg}$ was used under nitrogen flow [7]. 


\subsection{Electrochemical Characterization}

\subsubsection{Electrochemical Impedance Spectroscopy (EIS)}

Electrochemical impedance spectroscopy (EIS) analysis was conducted using AUTOLAB/AUT51018 (Metrohm Ltd, Herisau, Switzerland) (potential/galvanostat) in order to evaluate ionic conductivity of the developed CPEs. As shown in Figure 2, the system consisted of a separator containing the developed electrolytes placed between two stainless steel blocking electrodes where the testing was conducted within 0.1 to $10^{5} \mathrm{~Hz}$ frequency range at $303.15-383.15 \mathrm{~K}$ [24].

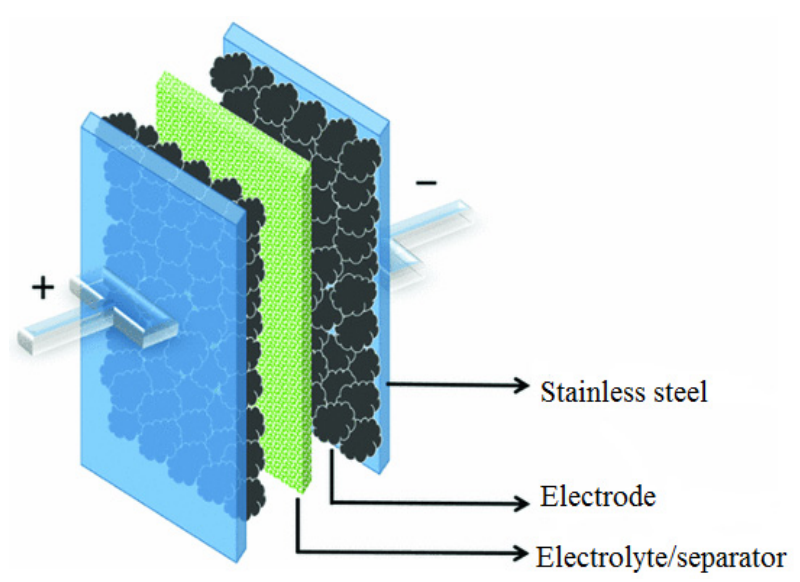

Figure 2. Schematic diagram showing 2-electrode system for electrochemical impedance spectroscopy (EIS) analysis.

Ionic conductivity of the prepared CPEs was calculated using Equation (1) as described previously [25]:

$$
\sigma=\frac{t}{R_{b} A}
$$

where $t$ is the thickness of the samples $(\mathrm{cm}), R_{b}(\Omega)$ is the bulk resistance, and $A$ is the electrode-electrolyte contact area $\left(\mathrm{cm}^{2}\right)$.

\subsubsection{Linear Sweep Voltammetry (LSV)}

Potential window or cell voltage of the prepared CPEs were studied using linear sweep voltammetry (LSV). The analysis was conducted at a scan rate of $10 \mathrm{mVs}^{-1}$ in the potential range from $-4 \mathrm{~V}$ to $4 \mathrm{~V}$ following the setup described in Figure 2 (AUTOLAB/AUT51018).

\section{Results}

\subsection{Structural Analysis of CPE}

The CPEs in this study were prepared by incorporating conducting salt $\left(\mathrm{K}_{2} \mathrm{CO}_{3}\right)$ and the filler $\left(\mathrm{SiO}_{2}\right)$ into the polymer host (PVA) as described in the experimental section. To elucidate the principle of ion conduction in CPEs, the mechanism of ion transport in polymer electrolytes was proposed as illustrated in the following scheme (Scheme 1). The $\mathrm{K}_{2} \mathrm{CO}_{3}$ can be easily dissociated into cations $\left(\mathrm{K}^{+}\right)$and anions $\left(\mathrm{CO}_{3}{ }^{2-}\right)$ upon interaction with the solvent (dissolution) as shown in Equation (2).

$$
\mathrm{K}_{2} \mathrm{CO}_{3(\mathrm{~s})} \longrightarrow \mathrm{K}^{+}{ }_{(\mathrm{aq})}+\mathrm{CO}_{3}{ }^{2-}{ }_{(\mathrm{aq})}
$$




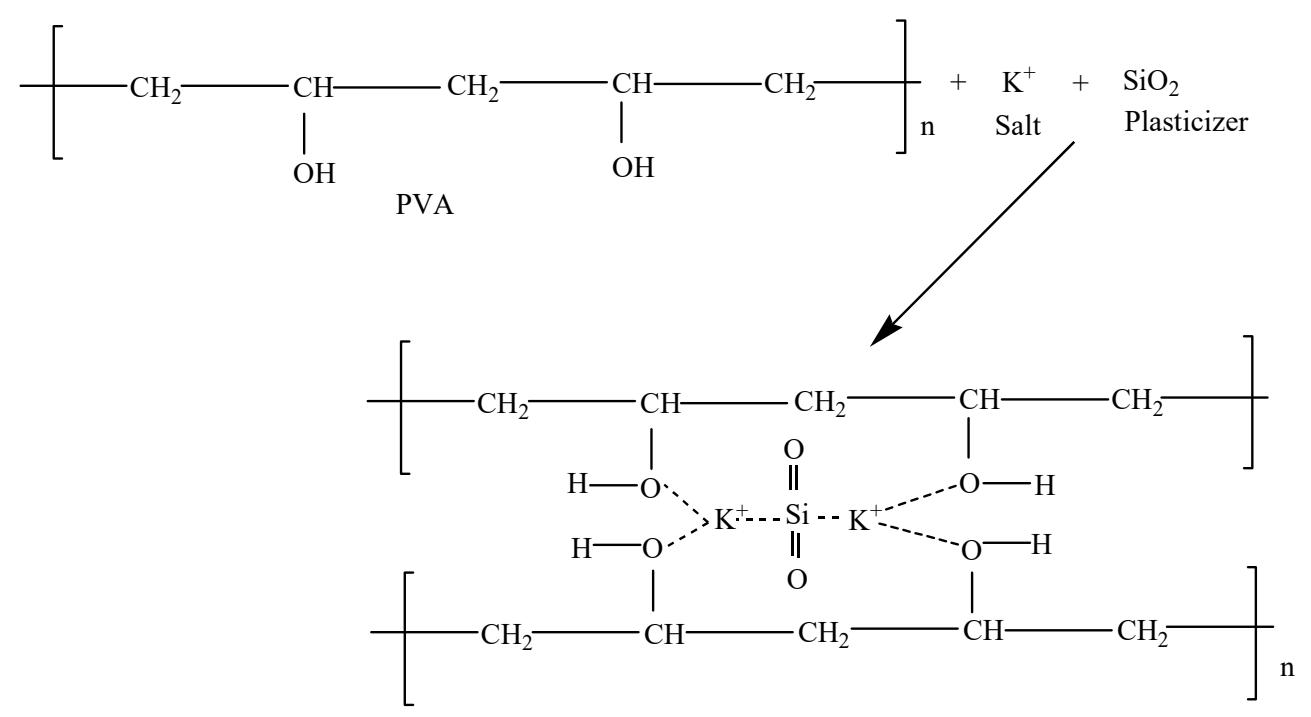

Composite polymer electrolyte

Scheme 1. Possible structure for the synthesized PVA- $\mathrm{K}_{2} \mathrm{CO}_{3}-\mathrm{SiO}_{2}$ composite electrolyte.

The $\mathrm{K}^{+}$chemically coordinates with the polar $(-\mathrm{H})$ groups of PVA in the presence of $\mathrm{SiO}_{2}$. This coordination results in the formation of weak bonds between hydroxyl group, $\mathrm{K}^{+}$, and the $\mathrm{SiO}_{2}$ which results in complex formation as shown in Scheme 1 [26].

In addition, the partial or weak bond formed between $\mathrm{K}^{+}$and $\mathrm{SiO}_{2}$ with the polar groups of the polymer could aid in hastening the conduction of ions since the ions are in a moveable state [26]. Similarly, silica material was found to affect the changes in the morphological structure of the electrolytes [20]. The silica external surface may chemically coordinate with the ions and subsequently deliver extra site generating favorable tunnels or ways for ion transport within the locality of the electrolytes [26]. The chemical coordination within the electrolytes might increase the conduction sites for the movement of ions, thus creating extra conducting ways for migration of ions [21,27]. Previous studies have reported that the silica particles incorporated into the polymer matrix could be blended with the electrolyte material and the conductivity can be improved. This can be credited to its greater volume division of the amorphous phase [28,29].

The linkage between the polymer polar groups, the cations $\left(\mathrm{K}^{+}\right)$, and the silica material creates a large amount of ion conducting site and a well improved interfacial coordination, accordingly resulting in improvement in ionic conductivity of the electrolyte [30]. The interactions between metal ions from the salts and the plasticizing effect from the silica with hydroxyl groups $(-\mathrm{OH})$ of the polymer result generally from electrostatic attractions and hence lead to the coordination bond formation. There are features that generally affect salt-polymer-filler coordinations, such as type of hydroxyl group bonded to the backbone of the polymer, region among the functional groups, molecular weight, compositions, nature and charge of metal cation, counter ions, and the degree of branching [31]. The cations from the salts move from one interaction site when an electric field was subjected to the system owing to the effect from the silica [32]. Previous studies reported that ions from the salt and the plasticizer that are connected with the hydroxyl groups transfer through re-coordination along the polymer backbone. Therefore, the chains of the polymer are doubled over to form channels, in which the ions (mostly cations) are coordinated and situated by the $\mathrm{OH}$ group of the polymer. These channels generate passages, providing ways for the ions' movement in the system [33].

Moreover, it was reported that addition of filler into the CPEs was found to decrease the number of active centers, and consequently weaken molecular forces between the polymer chains [32]. Hence, this leads to a decrease in the inflexibility of the host polymer and consequently disturbs the thermo-mechanical properties of the polymer $[30,31]$. Moreover, addition of filler was found to affect glass transition temperature $\left(T_{g}\right)$ of the 
polymer system [30]. Thus, this leads to the decrease in crystalline region of the composites and subsequently increases ion dissociations where a significant enhancement in charge carriers transport is achieved that leads to higher ionic conductivity. The formation of complex between polymer, salt, and the filler $\left(\mathrm{PVA}-\mathrm{K}_{2} \mathrm{CO}_{3}-\mathrm{SiO}_{2}\right)$ will lead to an increase in entropy, which results in the segmental motion being increased. The increase in segmental motion was reported to decrease crystallinity and improve flexibility of the electrolyte material [33]. The incorporation of silica particles into polymer backbone can increase the ion dissociation to yield more free cations for conductivity $[27,34]$.

\subsection{Physicochemical Characterization}

\subsubsection{Chemical Structure}

To affirm the interaction and coordination between salt, polymer, and the filler (silica) in CPEs, the FTIR spectra of the samples were analyzed and the result is presented in Figure 3 and Table 2. The absorption peak of the CPEs shows various peaks between $4000 \mathrm{~cm}^{-1}$ and $400 \mathrm{~cm}^{-1}$. The absorption spectrum at $3258 \mathrm{~cm}^{-1}$ band for the PVA $/ \mathrm{K}_{2} \mathrm{CO}_{3}$ with no $\mathrm{SiO}_{2}$ (PKS0) is attributed to the stretching of $\mathrm{O}-\mathrm{H}$ vibrations of alcohol group $[27,35]$. The broad peak appearing at $2941 \mathrm{~cm}^{-1}$ is associated with the asymmetric $\mathrm{C}-\mathrm{H}$ stretching. The sharp peak located at $1647 \mathrm{~cm}^{-1}$ is assigned to the $\mathrm{C}=\mathrm{O}$ stretching of carboxyl group [36]. The appearance of peaks in the region of $1562 \mathrm{~cm}^{-1}$ could be assigned to the strong $C=C$ stretching vibration from $\alpha, \beta$-unsaturated ketone of the polymer composites [37]. Furthermore, the peak at $1411 \mathrm{~cm}^{-1}$ belongs to bending vibrations of $\mathrm{CH}_{2}$ while the band $1141 \mathrm{~cm}^{-1}$ occurred because of the $\mathrm{CH}$ twitching vibrations. The bands at $1090 \mathrm{~cm}^{-1}$ belong to the $\mathrm{C}-\mathrm{O}$ broadening of the acetyl group present in the PVA structure while the absorption spectrum at $843 \mathrm{~cm}^{-1}$ has been allocated to $\mathrm{C}-\mathrm{H}$ rocking vibrations. Finally, the small peak at $657 \mathrm{~cm}^{-1}$ is assigned to the free $\mathrm{CO}_{3}{ }^{2-}$ anions, which indicates the mobility of the solvated $\mathrm{K}^{+}$and $\mathrm{CO}_{3}{ }^{2-}$ ions in the CPE system [38].

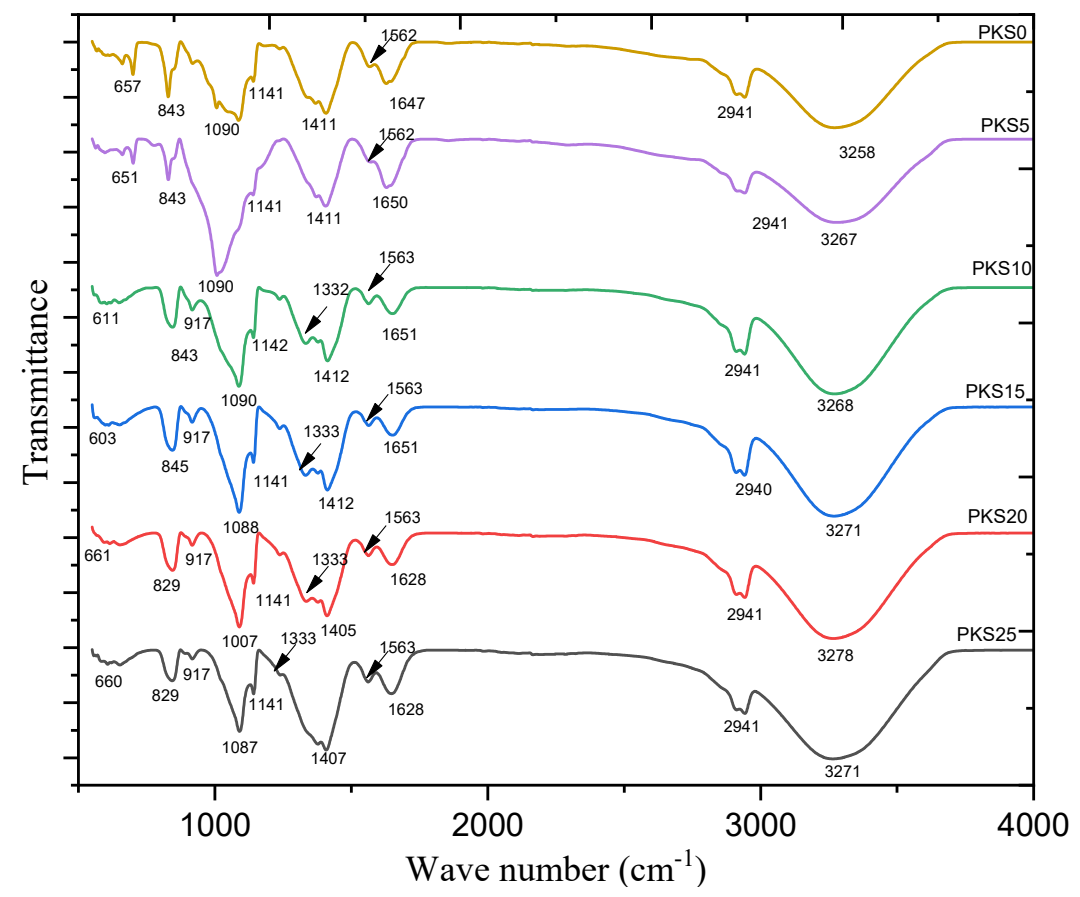

Figure 3. FTIR spectrum of PVA- $\mathrm{K}_{2} \mathrm{CO}_{3}$ (PKS0), PKS5, PKS10, PKS15, PKS20, and PKS25 composite polymer electrolytes. 
Table 2. Summary peaks $\left(\mathrm{cm}^{-1}\right)$ of the synthesized composite polymer electrolytes (PKS).

\begin{tabular}{cc}
\hline Description Vibration Modes & Wavenumber $\left.\mathbf{( c m}^{-\mathbf{1}}\right)$ \\
\hline Stretching of O-H of PVA & 3258 \\
Asymmetric C-H stretching of pure PVA & 2941 \\
C=O broadening & 1647 \\
Strong C=C broadening & 1562 \\
Winding vibration of CH ${ }_{2}$ & 1411 \\
CH wagging vibrations & 1141 \\
C-O stretching of acetyl group & 1090 \\
C-H rocking & 843 \\
Free anions & 657 \\
Symmetric Si-O-Si stretch & 917 \\
Asymmetric Si-O-Si stretch & 1332 \\
\hline
\end{tabular}

FTIR plots for samples PKS5 up to PKS25 depict the spectra of as prepared CPEs with $5,10,15,20$, and $25 \mathrm{wt} . \%$ of $\mathrm{SiO}_{2}$, respectively. It was observed that the peaks of $\mathrm{O}-\mathrm{H}$ widening, asymmetric $\mathrm{C}-\mathrm{H}$ widening, $\mathrm{C}=\mathrm{O}$ enlarging, $\mathrm{C}=\mathrm{C}$ broadening, and all other peaks were still found with few changes and little shifting in the peak intensities [7]. These changes and shifting in the peak intensities are reported to be important in order to establish the complex formation between the host polymer (PVA), salt $\left(\mathrm{K}_{2} \mathrm{CO}_{3}\right)$, and the filler $\left(\mathrm{SiO}_{2}\right)$. For instance, the shifting of hydroxyl band of the composite polymer electrolyte (PKS) from 3258 to $3271 \mathrm{~cm}^{-1}$ when blended with $\mathrm{SiO}_{2}$ and the formation of new spectrum at $917 \mathrm{~cm}^{-1}$, and $1333 \mathrm{~cm}^{-1}$ corresponding to symmetric and asymmetric Si-O-Si expanse, respectively, indicate the polymer-salt-silica complexation $[39,40]$. It was also observed from the spectra of the PKS15 that the peak of $\mathrm{CH}$ wagging at $843 \mathrm{~cm}^{-1}$ moved to higher wavenumbers $\left(845 \mathrm{~cm}^{-1}\right)$ than the other electrolytes, which designates shortened bond lengths of gel-like structures in the electrolytes [35,41]. These indicate that $\mathrm{SiO}_{2}$ interacts with PVA- $\mathrm{K}_{2} \mathrm{CO}_{3}$ in the form of a three-dimensional polymeric network (Scheme 1). In other words, $\mathrm{SiO}_{2}$ and PVA- $\mathrm{K}_{2} \mathrm{CO}_{3}$ chains exist in the form of CPEs [22].

\subsubsection{Miscibility and $\mathrm{SiO}_{2}$ Presence}

The surface morphology of the PVA- $\mathrm{K}_{2} \mathrm{CO}_{3}$ (PKSO) and the composite (PVA- $\mathrm{K}_{2} \mathrm{CO}_{3}$ $\mathrm{SiO}_{2}$ ) electrolytes were studied using FESEM and the results are presented in Figure $4 \mathrm{a}-\mathrm{f}$. Figure 4a shows the surface morphology of the non-filler or filler-free electrolyte (PKS0) and it was observed that the sample demonstrated a smooth and homogeneous surface showing great miscibility between salt $\left(\mathrm{K}_{2} \mathrm{CO}_{3}\right)$ and the polymer. Figure $4 \mathrm{~b}$-e shows some agglomeration between $\mathrm{PVA}, \mathrm{K}_{2} \mathrm{CO}_{3}$, and $\mathrm{SiO}_{2}$ proving successful accumulation of silica in the inter-spherulitic region (amorphous region) which further improved with an increase in amorphosity of the polymer due to incorporation of filler $[40,42]$. With the dispersion and incorporation of 5-15 wt. $\% \mathrm{SiO}_{2}$, the CPEs showed uniform and smooth surfaces with white granules and the formation of more porous structures, indicating better compatibility between host polymer, salt, and the filler as can be observed in Figure $4 \mathrm{~b}-\mathrm{d}$. It was also observed that incorporation of $5-15 \mathrm{wt} . \% \mathrm{SiO}_{2}$ particles changed the microstructure of the composites into a more amorphous structure and with development of some voids that serve as ion migration paths. The smooth surface of the electrolytes indicates the homogeneous dispersion of the $\mathrm{SiO}_{2}$ particles. This was possible due to formation of weak bonds between the hydroxyl group of the polymer $(-\mathrm{OH}), \mathrm{K}^{+}$, and the $\mathrm{SiO}_{2}$ [21]. As can be observed, $\mathrm{SiO}_{2}$ is presented as white granules in the $\mathrm{PVA}-\mathrm{K}_{2} \mathrm{CO}_{3}$ composites confirming successful dispersion of the filler and the formation of $\mathrm{PVA}-\mathrm{K}_{2} \mathrm{CO}_{3}-\mathrm{SiO}_{2}$ composites. Moreover, addition of $5-15 \mathrm{wt} . \%$ of filler gave a positive change to the microstructure of the electrolyte and this could be ascribed to the good coordination and adhesion between the surface matrix of the polymer and $\mathrm{SiO}_{2}$ owing to the good homogeneous dispersion [42]. The increase in amorphous nature of the composites is highly favorable for attaining strong interaction between electrolytes and other components in the systems. This structure would support an improvement in ionic conductivity of composite electrolytes [41]. 

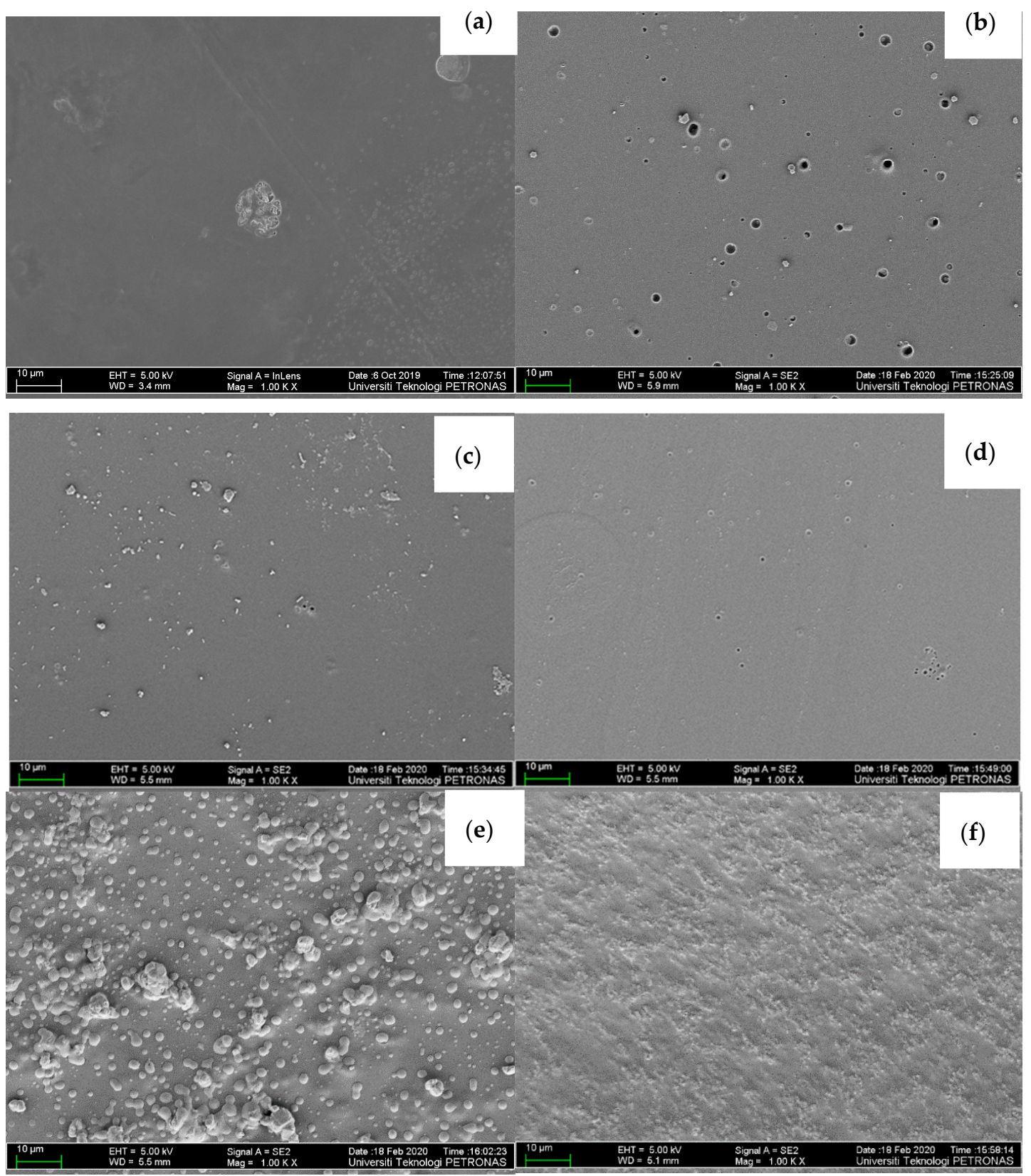

Figure 4. FESEM micrographs for the surface of (a) PKS0, (b) PKS5, (c) PKS10, (d) PKS15, (e) PKS20, and (f) PKS25 composite polymer electrolyte.

However, the surface became coarser with the addition of more than $15 \mathrm{wt} . \%$ (Figure $4 \mathrm{e}, \mathrm{f}$ ). Similarly, a substantial growth in the concentration of white granules was also observed, which could be attributed to recrystallization (formation of more crystalline region due to the high content of the silica) and aggregation of the filler in the polymer, since the polymer host is unable to accommodate large amounts of the $\mathrm{SiO}_{2}$ [42]. A previous study reported that large amount of filler may cause an uneven dispersion and agglomeration on the polymer matrix surface owing to the high surface energy and poor adhesion between polymer and the filler [40]. Hence, more agglomerations were observed in the composites with more than $15 \mathrm{wt} . \% \mathrm{SiO}_{2}$ which may lead to the loss of a significant amount of charge carriers that would subsequently lead to a decrease in conductivity $[10,42]$.

Correspondingly, Figure 5 presents results of energy-dispersive x-ray analysis (EDXA) analysis; it was observed that $\mathrm{Si}$ was successfully incorporated into the surface of the PVA- 
$\mathrm{K}_{2} \mathrm{CO}_{3}$ composites. This is anticipated to increase the amorphous region of the composites electrolytes that subsequently improved ionic conductivity of the CPEs.

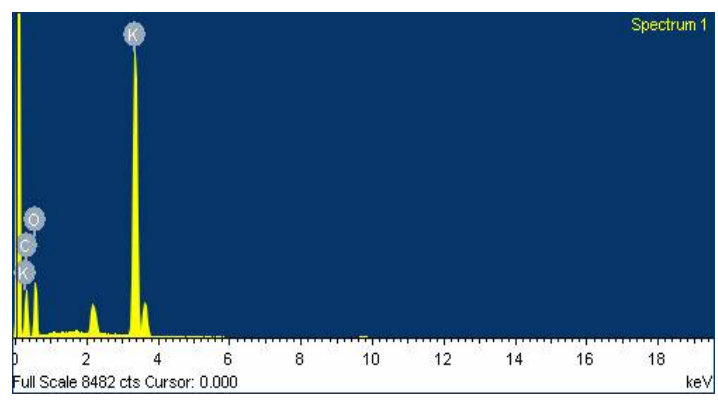

(a)

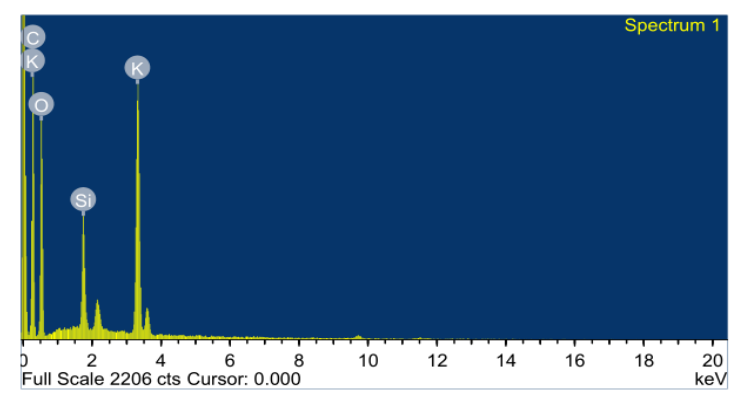

(b)

Figure 5. Energy-dispersive x-ray (EDX) plots representative of the composite polymer electrolyte (a) PKS0 and (b) PKS15, showing successful incorporation of $\mathrm{Si}$ into the $\mathrm{PVA}-\mathrm{K}_{2} \mathrm{CO}_{3}$.

\subsubsection{Thermal Stability}

Thermal stability is the most significant variables deciding stability and suitability of polymer electrolytes in every energy storage device [40]. Figure 6a,b portrays thermogravimetric analysis for filler-free electrolytes (PKS0) and electrolyte with fillers. The filler-free electrolytes show two major weight losses, one located around $50-102{ }^{\circ} \mathrm{C}$ that could be ascribed to the removal of water molecules owing to the hydroscopic nature of the polymer and impurities bonded to the polymer electrolytes. Another minor weight loss located at $102-185^{\circ} \mathrm{C}$ is attributed to the elimination of side-groups, chain scission, and the cessation of the PVA backbone at higher temperature as well as strong effect of the $\mathrm{K}_{2} \mathrm{CO}_{3}$ [29].
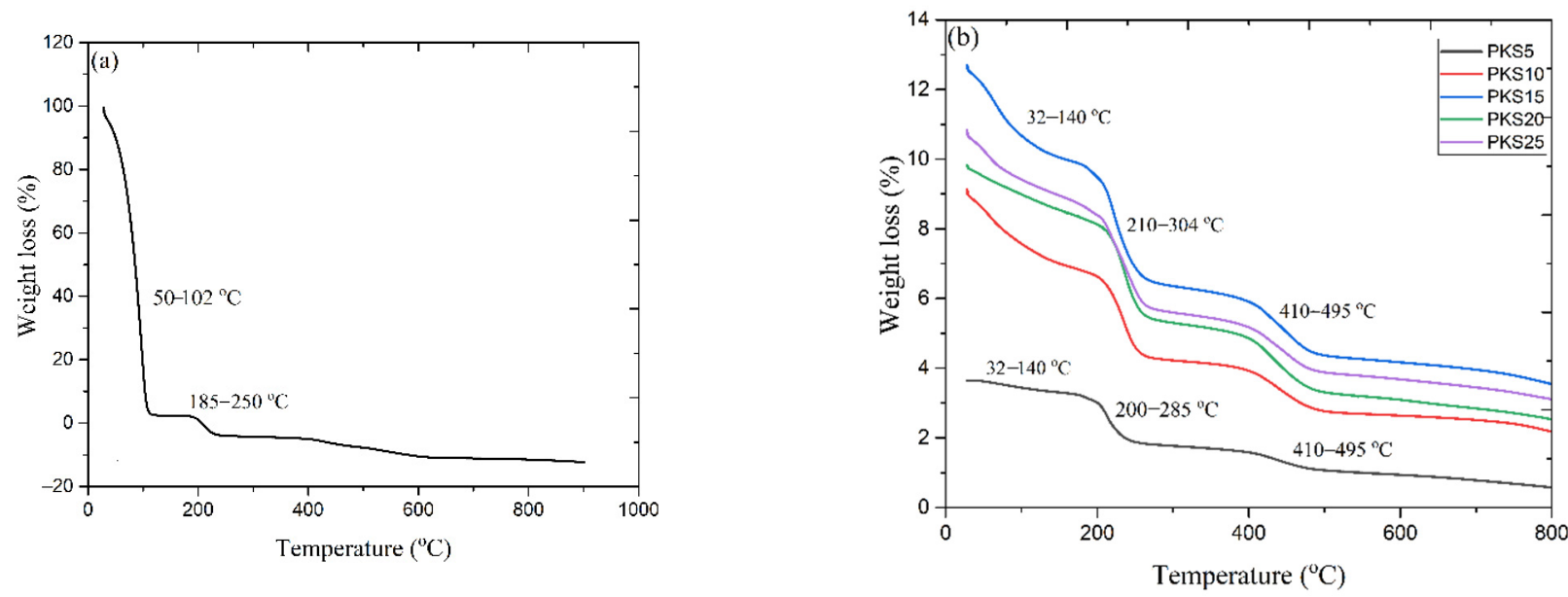

Figure 6. TGA thermograms of (a) PKS0 and (b) PKS5, PKS10, PKS15, PKS20, and PKS25 composite polymer electrolyte.

However, three thermal degradation steps were noticed for all samples with fillers. The first degradation was noticed around $32-140{ }^{\circ} \mathrm{C}$ because of the removal of moisture attached to the composites as described previously. The minor weight loss around this phase can be associated with the exclusion of unwanted objects in the samples [27]. The second step occurred between 210 and $304{ }^{\circ} \mathrm{C}$ while the third step followed between 410 and $495^{\circ} \mathrm{C}$. It has been confirmed that, the breakdown of polymer electrolytes especially PVA starts with chain "stripping", which might result in ether cross-linkage formation i.e., removal of water molecules together with the conjugated double bonds formation, generating polyene structures at temperature above $200^{\circ} \mathrm{C}$ as shown in Scheme $2[27,29,38]$. 


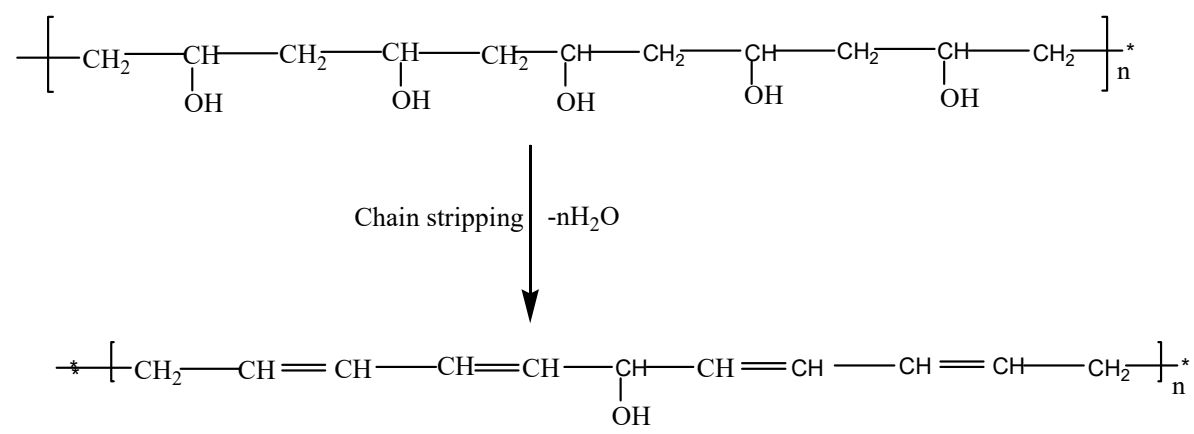

Scheme 2. Polymer chain stripping mechanism.

Upon addition of filler, the mass loss and the thermal decomposition were observed to increase significantly due to the presence of silica in the PVA matrix. This indicates the influence of the complex formation between the polymer, filler, and the salt [21]. The weight loss of samples with filler was observed to be greater than filler-free samples (210 and $304{ }^{\circ} \mathrm{C}$ ), which suggests that the highly conducting electrolytes display better thermal properties $[19,29]$. The final weight loss $\left(410\right.$ and $\left.495^{\circ} \mathrm{C}\right)$ is linked to the cessation of the PVA backbone [43]. At this temperature, the double bond of polyene structures shown in Scheme 2 would be broken down, and converted into low-molecular weight single bond aliphatic polymer products. Further than this phase, the polymer electrolytes' weight remains unaffected [29]. Based on TGA analyses, thus, it can be established that the incorporation of silica material into PVA matrix successfully improved the general stability of the polymer electrolyte based on PVA- $\mathrm{K}_{2} \mathrm{CO}_{3}-\mathrm{SiO}_{2}$ composites.

\subsubsection{Glass Transition Temperature}

To further study the effect of silica filler on the polymer-salt electrolytes, DSC analysis was conducted and recorded for different polymer electrolytes and the results are presented in Figure 7a,b. For PKS0, an endothermic peak at $90.95^{\circ} \mathrm{C}$ linked to the melting point $\left(T_{m}\right)$ of the polymer-salt electrolytes was observed. However, a decrease in the $T_{m}$ $\left(T_{m}=73-68{ }^{\circ} \mathrm{C}\right)$ of the electrolytes containing silica material was observed, indicating an increase in amorphous structure of the samples which is due to the incorporated $\mathrm{SiO}_{2}$ particles, as earlier discussed in FESEM results (Figure 4). This increase in amorphosity is associated with the good coordination between PVA and filler that decreased the extent of crystalline region of PVA into the amorphous region and subsequently improved the conductivity. The decrease in $T_{m}$ indicates that the transition from crystalline to amorphous phase has occurred, which has a vital role in the movement of ions. Therefore, an improvement in ionic conductivity is expected with the increase in $\mathrm{SiO}_{2}$ composition [10]. A similar study of decrease in $T_{m}$ was reported previously while incorporating silica into a polymer [22]. 

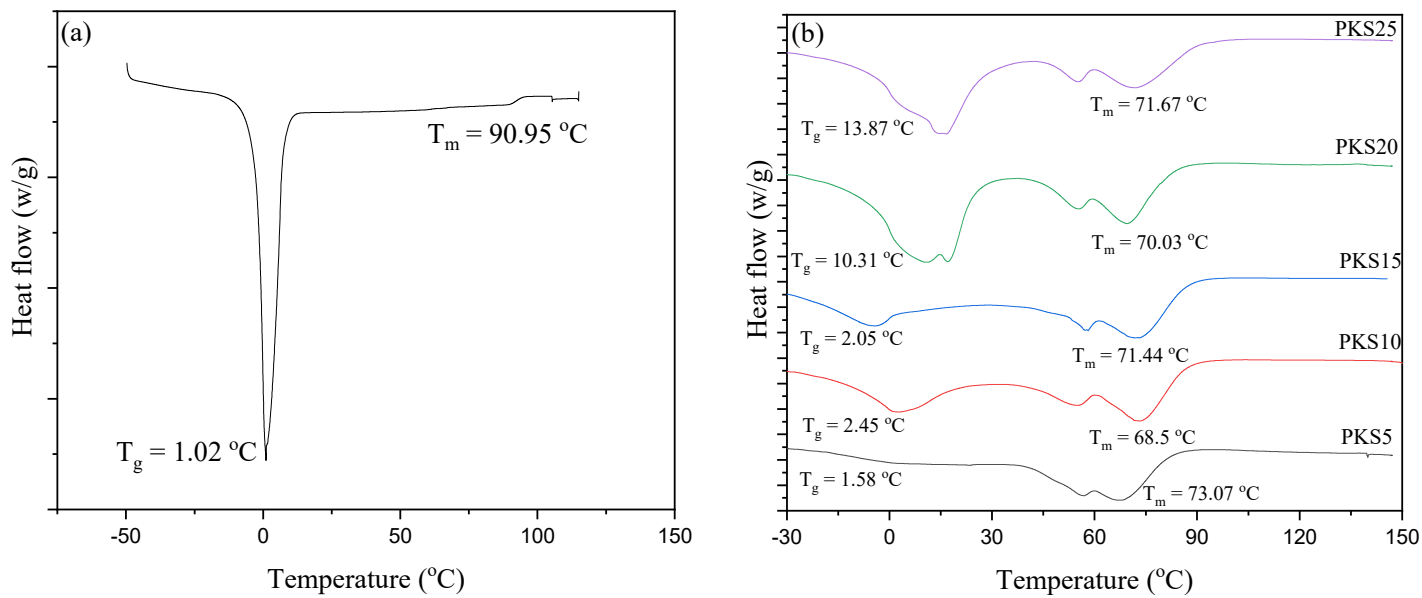

Figure 7. DSC scans for (a) PKS0 and (b) PKS5, PKS10, PKS15, PKS20 and PKS25 composite polymer electrolyte.

Conversely, addition of $\mathrm{SiO}_{2}$ was found to increase $T_{g}$ of the electrolytes as can be seen in Figure 7. It was reported that an increase in $T_{g}$ can affect polymer segmental motion and hence ionic conductivity. The values of $T_{g}$ of the entire electrolyte with fillers (PKS5PKS25) were observed to increase with the addition of the $\mathrm{SiO}_{2}$ showing the successful formation of composites. A previous study reported that the $T_{g}$ of polymer materials increases upon addition of plasticizers or fillers due to the partial coordination bonding during complex formation [44]. The increase of $T_{g}$ observed in this study indicates the effect of the $\mathrm{SiO}_{2}$ that relaxes the PVA backbone and hence yields bendable backbone that aids in stimulating easy migration of ions in the electrolyte systems [45]. The addition of plasticizer or filler into the polymer materials was reported to enhance ionic movement because of the growing ionic coordination in the host polymer [46]. Low $T_{g}$ could be attributed to the reduction in crystallinity due to the incorporation of the silica material. Polymers with low $T_{g}$ are desirable for delivering better plasticity of the PVA chains to provide faster ionic movement. This ionic movement in the systems of polymer matrix could be associated with the confined fundamental relaxations that are categorized by the $T_{g}$ of the polymer $[29,37,47]$.

\subsubsection{Crystal Phase}

XRD analysis allowed detection of crystalline or amorphous phases of the electrolyte before and after incorporation of $\mathrm{SiO}_{2}$ into the parent PVA- $\mathrm{K}_{2} \mathrm{CO}_{3}$. The XRD patterns of PVA- $\mathrm{K}_{2} \mathrm{CO}_{3}$ (PKSO) and PVA- $\mathrm{K}_{2} \mathrm{CO}_{3}-\mathrm{SiO}_{2}$ are shown in Figure 8. It is clear that the natural framework structure of PVA- $\mathrm{K}_{2} \mathrm{CO}_{3}$ was conserved after incorporation of lower wt.\% (5-15 wt.\%) of $\mathrm{SiO}_{2}$ which could be attributed to the good dispersion of $\mathrm{SiO}_{2}$ into the PVA- $\mathrm{K}_{2} \mathrm{CO}_{3}$ matrix and good miscibility between $\mathrm{PVA}, \mathrm{K}_{2} \mathrm{CO}_{3}$, and $\mathrm{SiO}_{2}$ which leads to the successful PVA- $\mathrm{K}_{2} \mathrm{CO}_{3}-\mathrm{SiO}_{2}$ composite formation. As can be observed, PKS5 shows broad and distinct characteristic structure, and this could be partly attributed to the initial dispersion and incorporation of the filler into the surface of the polymer matrix and to the weak crosslinking reactions between the polymer matrix and the filler due to the low amount of the $\mathrm{SiO}_{2}$ content [17]. The results revealed that the incorporation of moderate amounts of filler (5-15 wt.\%) had a significant effect on the electrolyte and did not cause any serious change in morphology of the PVA- $\mathrm{K}_{2} \mathrm{CO}_{3}$, and the amorphous structure of the electrolyte was almost completely preserved which may result in significant increase in conductivity of the PVA- $\mathrm{K}_{2} \mathrm{CO}_{3}-\mathrm{SiO}_{2}$ electrolyte. It was reported that the amorphous characteristics of the composite electrolyte after successful incorporation of filler was found to accelerate ionic transport in the polymer framework, which further enhanced the ionic conductivity of the CPE $[11,27]$. 


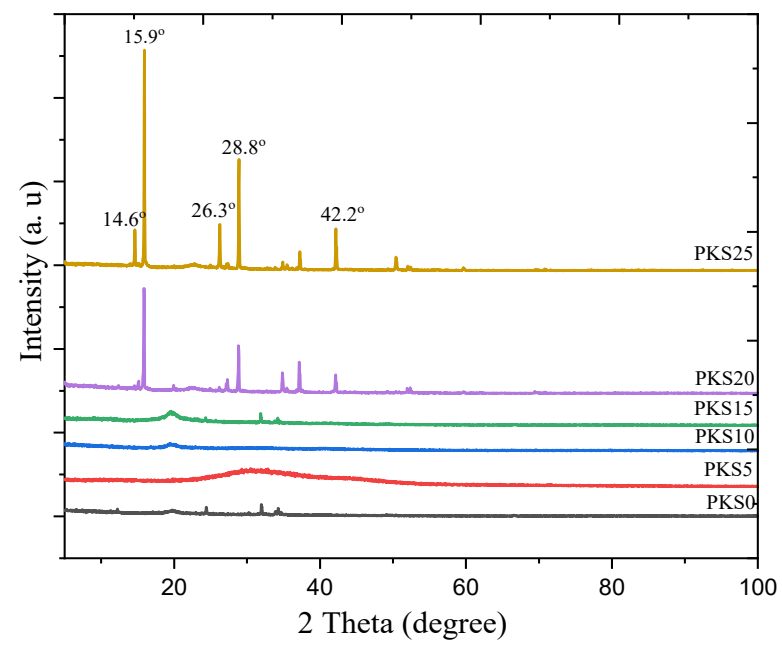

Figure 8. The XRD patterns of PKS0, PKS5, PKS10, PKS15, PKS20, and PKS25 for PVA- $\mathrm{K}_{2} \mathrm{CO}_{3}$ $\mathrm{SiO}_{2}$ composites.

However, new peaks appeared after incorporation of higher weight percentages of $\mathrm{SiO}_{2}(20-25 \mathrm{wt} . \%)$ with characteristic diffraction pattern of chabazite phase showing $\mathrm{Si}$ peaks at $2 \theta=14.6^{\circ}, 15.9^{\circ}, 26.3^{\circ}, 28.8^{\circ}$, and $42.2^{\circ}$ corresponding to $\left(\begin{array}{lll}1 & 0 & 1\end{array}\right),\left(\begin{array}{lll}1 & 1 & 0\end{array}\right),\left(\begin{array}{lll}0 & 2 & 1\end{array}\right)$, (2 20 ), and (202) planes, respectively. This confirmed the successful dispersions of $\mathrm{SiO}_{2}$ into the parent PVA- $\mathrm{K}_{2} \mathrm{CO}_{3}$. Consequently, a substantial increase in crystallinity was observed which could be attributed to the recrystallization and aggregation of the filler in the PVA- $\mathrm{K}_{2} \mathrm{CO}_{3}$ since the polymer host is unable to accommodate large amount of the filler [42].

\subsection{Electrochemical Properties}

\subsubsection{Resistance}

A previous study reported that the conductivity of CPEs depends mainly on ionic mobility and the concentration of ion carriers $[10,48]$. Thus, the EIS technique was used to evaluate ionic conductivity and ionic conductors in the polymer electrolytes and to understand the electrode-electrolyte interface behavior. Figure $9 \mathrm{a}, \mathrm{b}$ shows the results of the EIS analysis for all samples with different amount of filler at $373.15 \mathrm{~K}$. It can observed that the distinctive Cole-Cole plot of the PKS0 (Figure 9a) consists of a broadened semicircle at a higher frequency region with tilted spike, suggesting that the electrolyte is partly resistive and capacitive in nature [48]. The semicircle at the high frequency region is associated with the parallel combination of a resistor and a capacitor and a low frequency spike signifies formation of double layer capacitance at the electrode-electrolyte interface owing to ion migration at low frequency [49].

However, with the successful incorporation of filler, the semicircle of the un-plasticized sample disappeared which could be attributed to the increase in amorphous region of the polymer matrix that led to a decrease in (bulk) resistance. Hence, the Cole-Cole plots of the CPEs containing filler (Figure $9 \mathrm{~b}-\mathrm{f}$ ) consist of a tilted spike at both high- and low-frequency regions which indicates that only the resistive component of the polymer material presents in the sample [25]. Similarly, in the EIS result, the capacitor must display a tilted spike when it is taken to be perfect [10]. It was reported that the long tails with no circle observed in the impedance plots denote the role of the ions or charge carrier dispersion and the effect of blocking electrodes (electrode polarization), hence their buildup at the interface of the electrode and electrolyte [49]. This increase of charge carriers at the interface of the electrode and electrolyte results in electrical double layer capacitances. The low and high frequency spike signifies double layer capacitance formation at the interface of electrode and electrolyte which could be associated with the movement of charge carriers at lower 
frequency [11]. Likewise, the linearly rising spike in the EIS plot reveals the high absorption of ions and thus specifies the capacitive nature of the system [50].
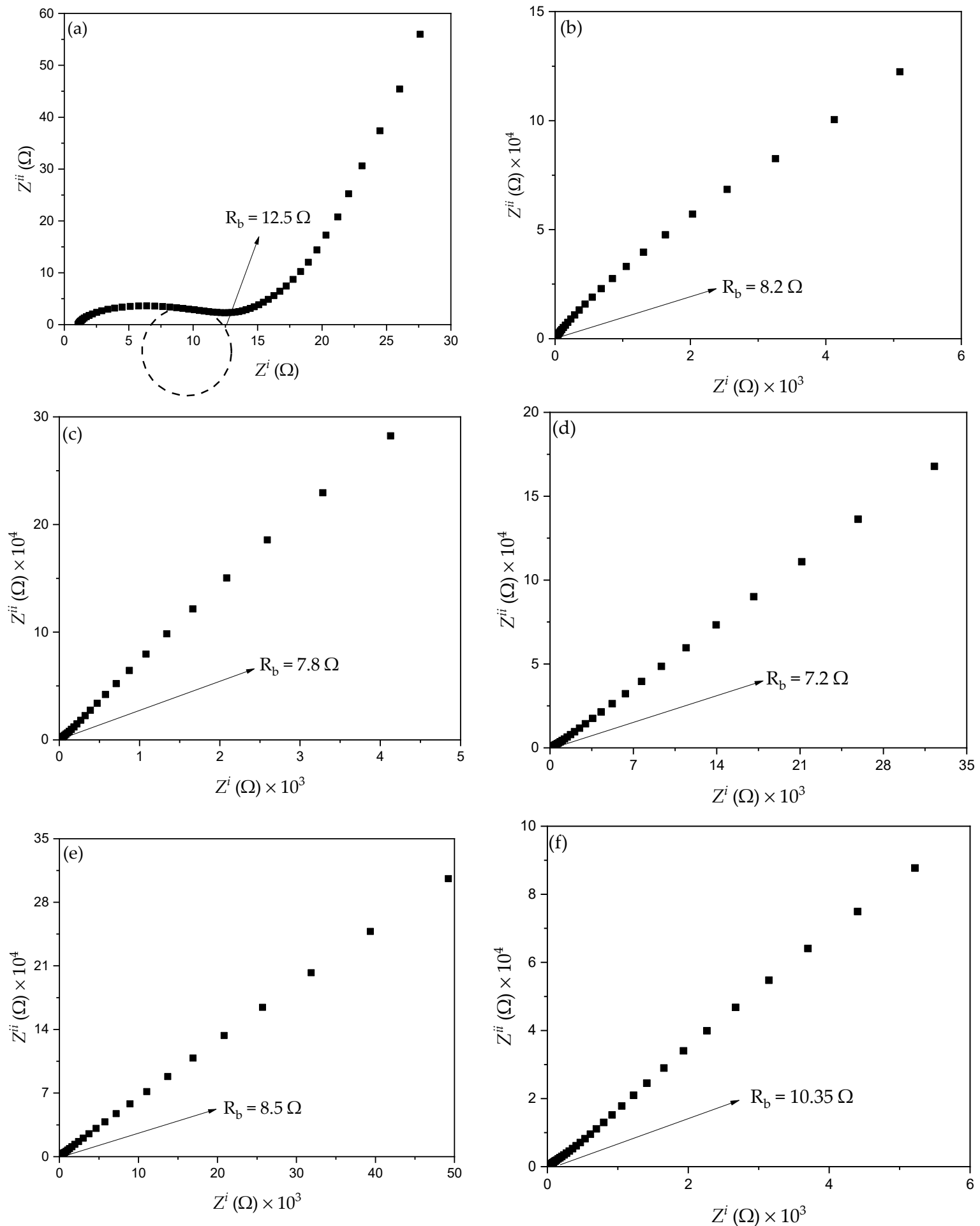

Figure 9. Cole-Cole plots for (a) PKS0, (b) PKS5, (c) PKS10, (d) PKS15, (e) PKS20, and (f) PKS25 composite polymer electrolytes at $373.15 \mathrm{~K}$.

From the plots in Figure 9, the resistance at the high frequency region is obtained from the intercepts on the $x$-axis of the complex EIS plots. This resistance is known as the bulk resistance $\left(R_{b}\right)[27,51]$. The $x$-axis intercept from the high frequency reveals the bulk properties of the electrolytes [47]. $R_{b}$ decreased with the increase in filler from 5 to $15 \mathrm{wt} . \%$ 
owing to the increase in carrier density and ion mobility $\mu_{i}$. It was also observed that the successful incorporation of $\mathrm{SiO}_{2}$ into PVA helped salt (ion) dissociation, thus decreasing the formation of ion aggregates. It was found that $R_{b}$ of PKS15 was lower when compared with $R_{b}$ of other samples. This could be associated with the fact that PKS15 appears to be more amorphous as observed in FESEM and DSC results (Figures 4 and 7). Furthermore, high effect of $\mathrm{SiO}_{2}$ particles was a significant factor in reducing $R_{b}$ of the polymer material. This indicates the actual effect of $\mathrm{SiO}_{2}$ in increasing the interfacial contact at the electrode and electrolyte system. The movement and diffusion of ions or charge carriers in the electrode-electrolyte system might similarly be improved with low $R_{b}$, causing an increase in ionic conductivity [41].

However, an increase in $R_{b}$ with increase in $\mathrm{SiO}_{2}$ particles beyond 15 wt.\% was observed and this can be associated with the high $T_{g}$ (Figure 7) value of the samples that led to an increase in crystallinity of the polymer material. When high amount of $\mathrm{SiO}_{2}$ particles were incorporated into the polymer matrix, more crystalline phases were introduced to the electrolyte system, consequently leading to the increase in $R_{b}$. It is very obvious that the crystalline phase in polymer matrix blocks the ionic motion and consequently causes a decrease in conductivity [10]. This is in agreement with the FESEM results discussed in Figure 4e,f where a substantial increase in the concentration of white granules was detected which could be attributed to the recrystallization and aggregation of the polymer electrolyte.

Further, an equivalent circuit of the EIS plots was proposed as shown in the inset of Figure 9a in order to provide information about interface properties of the electrolytes. The high frequency semicircle region of the EIS plots was made by a parallel combination of a capacitor and resistor, as denoted in the equivalent circuit model. The bulk properties $\left(R_{b}\right)$ of the electrolytes denote the capacitance and interfacial contact between the electrodes [2]. The capacitor represented by the capacitance of double layer $\left(\mathrm{C}_{\mathrm{dl}}\right)$ marks the formation of electrical double layer owing to the increase in charge carrier concentration at the electrode-electrolyte interface due to the diffusion of ions into the porous surface of the electrode and consequently provide high ionic conductivity. The $C_{\mathrm{dl}}$ was joined in parallel with charge transfer resistance $\left(R_{c t}\right)$ and a capacitance that were incorporated in series in order to evaluate the contribution of pseudocapacitance [10]. Thus, the results established that the successful incorporation of $\mathrm{K}_{2} \mathrm{CO}_{3}$ and $\mathrm{SiO}_{2}$ into the polymer increase ion diffusion in the electrolyte system and therefore support adsorption of ions at the electrode-electrolyte interface, which leads to the increase in ionic conductivity [23]. The resistance $\mathrm{R}_{\mathrm{ct}}$ signifies charge transfer resistance of the CPEs on the charge absorption across the electrode/electrolyte interfaces. Hence, the ions are essential to overcome the resistance in order to form the electrical double layer. The total internal resistance of the cell, which is the combination of $R_{b}$ and $R_{c t}$ was computed from the intercept of the semicircle [2].

\subsubsection{Ionic Conductivity}

To study the effect of filler on ionic conductivities based on $\mathrm{PVA}-\mathrm{K}_{2} \mathrm{CO}_{3}$ composites, the ionic conductivities were measured as a function of silica content at $373.15 \mathrm{~K}$. Figure 10 depicts the ionic conductivity of the synthesized samples at different wt.\% silica content calculated using impedance results by applying Equation (1). As can be observed, with the inclusion of the silica particles, the conductivity improved. This conductivity continued to slowly increase with the incorporation of 5-15 wt.\% of silica particles (PKS15). The highest conductivity of $7.86 \times 10^{-3} \mathrm{mScm}^{-1}$ was achieved at $15 \mathrm{wt} . \%$ of $\mathrm{SiO}_{2}$ as compared to conductivity of the non-filler electrolytes (PKS0) of $4.50 \times 10^{-3} \mathrm{mScm}^{-1}$. The improvement in conductivity can be ascribed to the influence of the $\mathrm{SiO}_{2}[29,52]$. Strong influence of $\mathrm{SiO}_{2}$ helps to temper with the PVA-salt complexation and thus enhanced the plasticity of the PVA chain. The influence of the $\mathrm{SiO}_{2}$ aids ions to be easily migrated in the PVA chain with very flexible chains polymer [21,53]. 


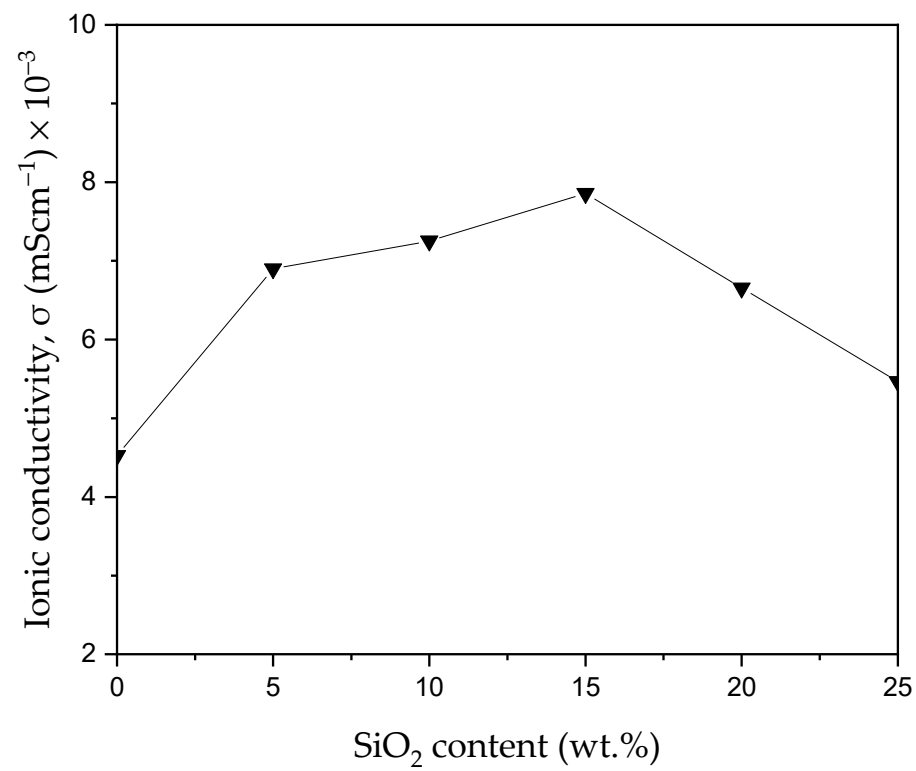

Figure 10. Plots of conductivity of the PVA-salt-SiO $2 ~ C P E$ with different $\mathrm{SiO}_{2}$ contents at $373.15 \mathrm{~K}$.

Moreover, $\mathrm{SiO}_{2}$ enhanced the amorphous region of the polymer, which results in weakening the temporary coordinative bonds between the molecules in the crystalline phase and transforming the polymer into flexible complexes [39]. Likewise, filler encourages the conduction process through provision of new conducting sites. This could be achieved by coordinating the cations from the salt with the polar groups of the side chain in the backbone of polymer [53]. This coordination not only offers more sites for the conduction process, but also offers more ions in the composites. This also results in additional free charge carriers [25]. Moreover, with the successful dispersion of silica particles into the polymer-salt complex, an active ionic tunnel for the conduction process was created with the double layer formation. This led to enhancing the electrical potential between the electrodes when the electric field is applied. This results in the assumption that the charge carriers are mobile ions as discussed in EIS analysis [22]. Consequently, the highest conductivity was achieved in the PKS15 electrolyte. This type of effect by the filler was also reported earlier, where the complexations between the polymer and the ions were affected by the silica material [53]. As suggested earlier, the $\mathrm{SiO}_{2}$ particles as a filler can also act as a "solvent" to stimulate dissociation of ions that subsequently increase the ionic conductivity [54].

However, when the amount of filler exceeds $15 \mathrm{wt} \%$, the conductivity starts to decline. This shows that the greater amount of filler did not contribute to the increase in conductivity. High amounts of $\mathrm{SiO}_{2}$ resulted in the re-crystallization process (seen in FESEM result, Figure 4e,f) in the composites which caused the PVA chains to become inflexible and thus significantly reduced the movement of ions [21]. Similarly, the decrease in ionic conductivity at higher amounts of filler can be ascribed to the agglomeration of charge carriers in the polymer electrolytes. Excessive ions in the polymer matrix were reported to cause the formation of aggregates and ion pairs. These aggregates might cause the blocking of the ions tunnels (ways) and deter the migration of ions in the systems, which leads to a decrease in conductivity. In addition, the number of ions available for conduction is decreased in the presence of ion aggregates. At a high amount of filler, the cations $\left(\mathrm{K}^{+}\right)$from the salt could relatively form pairs with anions instead of providing carrier charges for ion movement $[17,29]$. These cations form neutrals with anions from the hydroxyl group of the polymer and hence transform the cations into an immovable state. Consequently, the conducting sites of the polymer electrolytes could be reduced and eventually decrease the conductivity. These aggregates and neutral pairs obstruct the conducting ways and decrease the flexibility of polymer $[55,56]$. Similarly, an increase in $T_{g}$ is related to the increase in the crystalline nature of the polymer. Thus, conductivity 
decreases with the increase in $T_{g}$. As can be observed samples with highest $T_{g}$ values (PKS20 and PKS25) exhibited lowest conductivity since conductivity is higher when the electrolytes are in amorphous form.

The values of ionic conductivity achieved in this study were higher with more than two orders of magnitudes than the values reported earlier using different plasticizers / fillers $[57,58]$. Table 3 compares the results obtained in this study with previous studies earlier reported. It can be observed that the prepared electrolyte in this study produced higher ionic conductivity at ambient temperature than other electrolytes reported using different plasticizers / fillers such as $\mathrm{MoO}_{3}$ [57], $\mathrm{KI}$ [58], $\mathrm{NH}_{4} \mathrm{I}$ [59], and $\mathrm{NH}_{4} \mathrm{Br}$ [60]. The higher performances displayed by the prepared electrolyte in this study could be due to the strong effect of silica particles that helps ions to be easily migrated in the PVA chain with very flexible chains polymer. Similarly, the ability of the prepared electrolyte to stick and penetrate into the porous structure of the fiber (separator) due to the excellent penetrating and sticking ability of the gel electrolyte could be another reason for achieving higher conductivity and potential window.

Table 3. Electrochemical properties of the synthesized composite polymer electrolytes in comparison with previous studies at room temperature.

\begin{tabular}{|c|c|c|c|}
\hline Electrolytes & Plasticizers & $\sigma,\left(\mathrm{mScm}^{-1}\right)$ & Ref \\
\hline PVA- $\mathrm{K}_{2} \mathrm{CO}_{3}$ & $\mathrm{SiO}_{2}$ & $3.25 \times 10^{-4}$ & This study \\
\hline $\mathrm{Li}_{2} \mathrm{O}-\mathrm{LiF}-\mathrm{P}_{2} \mathrm{O}_{5}$ & $\mathrm{MoO}_{3}$ & $4.40 \times 10^{-7}$ & [61] \\
\hline $\begin{array}{c}\text { Lithium polystyrene } \\
\text { sulfonate brushes (LiPSS) }\end{array}$ & $\mathrm{SiO}_{2}$ & $7.20 \times 10^{-4}$ & [61] \\
\hline PVC & $\mathrm{SiO}_{2}$ & $5.0 \times 10^{-4}$ & [61] \\
\hline $\mathrm{PEO} / \mathrm{PEG}$ & KI & $5.27 \times 10^{-5}$ & [58] \\
\hline Starch-chitosan doped with $\mathrm{NH}_{4} \mathrm{I}$ & Glycerol & $1.28 \times 10^{-3}$ & [53] \\
\hline Starch-chitosan & $\mathrm{NH}_{4} \mathrm{I}$ & $3.04 \times 10^{-4}$ & [59] \\
\hline Chitosan-based solid biopolymer & $\mathrm{NH}_{4} \mathrm{SCN} /$ glycerol & $1.51 \times 10^{-3}$ & [62] \\
\hline Chitosan & $\mathrm{NH}_{4} \mathrm{Br}$ & $2.15 \times 10^{-4}$ & [60] \\
\hline Chitosan-PEO NH $\mathrm{NH}_{3}$ & Ethylene carbonate (EC) & $2.06 \times 10^{-3}$ & [63] \\
\hline
\end{tabular}

\subsubsection{Temperature-Conductivity Relationship}

Figure 11 portrays ionic conductivity which is the most important parameter for polymer electrolytes against $1000 / \mathrm{T}$ of the prepared polymer electrolytes in the temperatures between $303.15-383.15 \mathrm{~K}$. The results show that the ionic conductivity slowly increased with the increase in temperature for all the prepared electrolytes. This increase in conductivity with increase in temperatures could be attributed to the transformation of PVA from semi-crystalline to an amorphous phase. Previous reports similarly linked the increase in conductivity with the temperature increase to the transformation of polymer matrix from semi-crystalline to an amorphous nature [64]. It was reported that formation of the amorphous phase in the polymer electrolytes helps ease migration of ions or charge carriers. This is because as the temperature increase, an amorphous phase of the PVA slowly increases, which helps polymer chain acquire rapid internal vibrations whereby a segmental motion is created owing to the bond spins. This successfully helps in ionic migrations and consequently results in an enhancement in ionic conductivity [65]. 


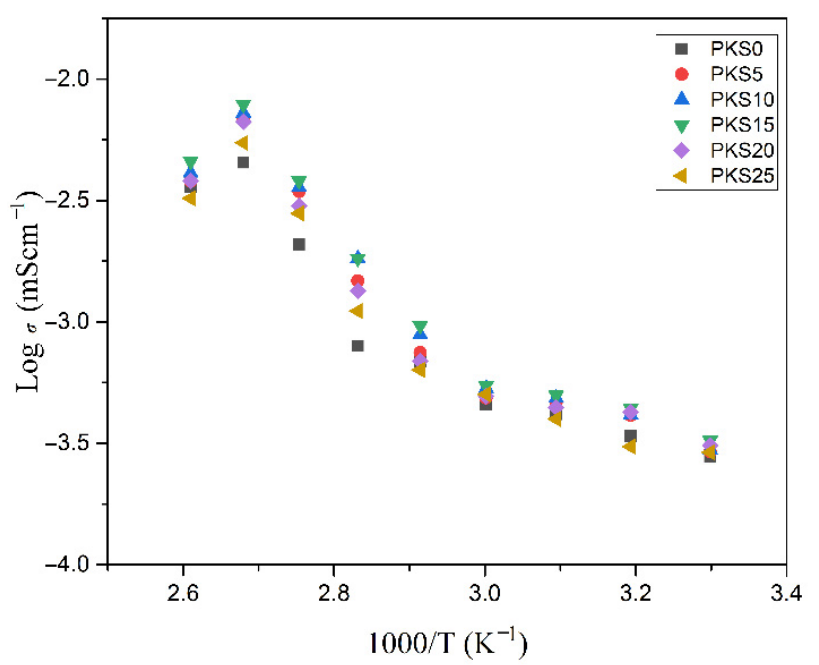

Figure 11. Conductivity versus temperature of $\mathrm{PVA}-\mathrm{K}_{2} \mathrm{CO}_{3}-\mathrm{SiO}_{2} \mathrm{CPEs}$.

It can be observed that the prepared electrolyte in this study exhibits mixed behaviors of Arrhenius and Vogel-Tammann-Fulcher (VTF) models. For instance, the linear increment in conductivity with the rise in temperature from 303.15 to $333.15 \mathrm{~K}$ suggests that migration of charge carriers or ions occurs over the temperature-activated routes and hence follows Arrhenius trend [64]. As shown in Figure 11, ionic conductivity increased linearly with the rise in temperature from $303.15 \mathrm{~K}$ until $333.15 \mathrm{~K}$ before it began to form a curve at higher temperatures (above $333.15 \mathrm{~K}$ ). This could be attributed to the enlargement of polymer matrix with the increase in temperature, which creates an empty space or free volume where ionic movement occurs. This subsequently enhances the movement of charge carriers or ions and lessens the ion cloud influence at the electrode and electrolyte system. Therefore, the linear relationships noticed in all the electrolytes at the stated temperatures indicate that the temperature dependency of ionic conductivity in the temperature range considered is of Arrhenius type given by Equation (3) [31]:

$$
\sigma=\sigma_{o} \exp \left(\frac{-E_{a}}{k_{B} T}\right)
$$

where $\sigma_{o}$ is a pre-exponential factor, $E_{a}$ is the activation energy, $k_{B}$ is the Boltzmann constant, and $T$ is the temperature $(\mathrm{K})$.

Previous studies reported that rise in temperature may affect fast vibration modes of the molecules, which stimulates the rotation of bonds in the polymer [10]. Moreover, the ionic association within the polymer segmental motion could be easily separated from the weak bonds with the hydroxyl groups at higher temperature. Hence, ionic motion improved with increase in temperature. The amplitude of the mode of vibrations was found to improve with the increase in temperature and consequently, the thermal vibration increases the decoupling level of charge carriers [28]. More ions could migrate in the polymer matrix with greater decoupling frequency as the number of mobile ions that is responsible for ionic movement increases and hence more ionic conduction would be generated resulting in higher ionic conductivity. In addition, the polymer matrix could be expanded because of the higher amplitude of vibration at higher temperatures. Hence, this generates more space for the conduction process, which leads to ions decoupling and easily migrating, and results in ionic conductivity increase $[10,53]$.

Consequently, at temperatures above $333.15 \mathrm{~K}$, all the electrolytes exhibited a VTF model behavior by forming a curvature. Here, to have better understanding into the temperature dependence of the conductivity, $\sigma$ above $333.15 \mathrm{~K}$, the conductivity data were 
fitted to the VTF equation. The VTF equation, which has been used to describe various dynamical processes in glassy and polymeric systems, is expressed as in Equation (4) [31]:

$$
\sigma(T)=A T^{-1 / 2} \exp \left[-\frac{B}{k_{B}\left(T-T_{0}\right)}\right]
$$

where $A$ is a pre-exponential factor, $k_{B}$ is the Boltzmann constant, $B$ is the pseudo-activation energy, $T_{0}\left(T_{0}=T_{g}-50 \mathrm{~K}\right)$ is the absolute temperature, and $T_{\mathrm{g}}$ is the glass transition temperature. Previous studies attributed the non-linear behavior of conductivity to the polymer segmental motion, which assisted in mobility of ions. Similarly, it has been reported that the curvature or non-linearity behavior of ionic conductivity versus temperature of polymer electrolytes could be attributed to the fact that the ion transport model is assisted by the polymer segmental motion $[29,64]$. Based on the VTF model, the curving behavior of the Arrhenius plots with the rise in temperature could be ascribed to the existence of a strong inter-relation between the ionic motion and polymer segmental relaxation. This also implies that the polymer segmental motion and ionic motion are well coupled with each other. Therefore, it is clear from this finding on Arrhenius and VTF models that the increase in ionic conductivity with the increase in temperature could be associated with the increment in both segmental mobility and hopping rate [9]. Moreover, dielectric constant and ion dissociation energy was reported to have a great influence on the conductivity behavior of a polymer electrolyte [31].

However, the conductivity of all the synthesized electrolytes was observed to decrease at temperatures greater than $373.15 \mathrm{~K}$. This decrease can be ascribed to the generation of grain boundaries within the polymer matrix which causes restrictions of ions hopping, which subsequently increases the resistance within the bulk of the material [66].

\subsubsection{Activation Energy (Ea) of Plasticized CPE}

To determine the ion dynamic of the prepared electrolytes further, activation energy $\left(E_{a}\right)$ was computed by fitting it in the Arrhenius equation (Equation (3)) [67]. Figure 12 illustrates the result of the activation energy as a function of $\mathrm{SiO}_{2}$ concentration. The results show that activation energy decreased significantly with the increase in $\mathrm{SiO}_{2}$ concentration up to $15 \mathrm{wt} \%$ (highest conducting electrolytes). However, with the incorporation of $\mathrm{SiO}_{2}$ content beyond $15 \mathrm{wt} . \%$, the $\mathrm{E}_{\mathrm{a}}$ suddenly increased. The sample with $15 \mathrm{wt} . \% \mathrm{SiO}_{2}$ gave the highest conductivity, hence the sample with the lowest $E_{a}\left(5.51 \times 10^{-4} \mathrm{eV}\right)$ suggesting that PKS15 may have the highest ionic motion (hopping) [68]. As discussed earlier, addition of filler was found to disrupt the interaction between the polymer backbones [69]. Thus, it requires lesser energy to break and reform the coordination bond among the polymer matrix. As a result, the ion diffusion is more favorable and this enhances the ionic conductivity [70].

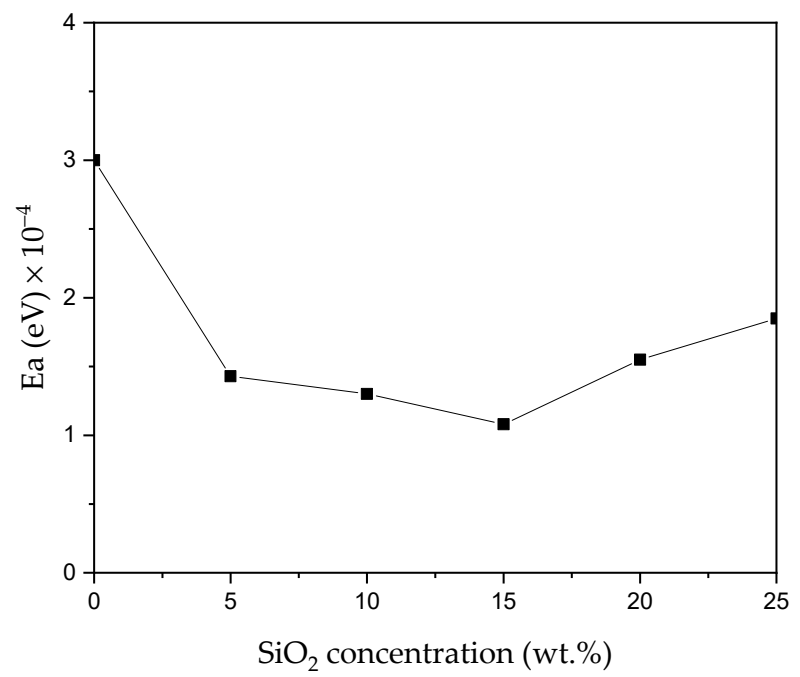

Figure 12. Activation energy $\left(E_{a}\right)$ versus $\mathrm{SiO}_{2}$ concentration. 
The result of Ea obtained in this study is in accordance with the previous studies. For instance, Wang and co-authors [71] reported that the highest conducting sample in all-solid-state electrolytes with a conductivity of $1.608 \times 10^{-4} \mathrm{Scm}^{-1}$ had the lowest activation energy $(0.367 \mathrm{eV})$. This implies that the ions in highly conducting samples require lower energy for migration. Lower activation energy also resulted from the short distance between transit sites provided by the blended polymers. Table 4 presents the summary of activation energies for all the prepared CPEs.

Table 4. Activation energy $\left(E_{a}\right)$ of the synthesized CPEs based on $\mathrm{PVA}^{-} \mathrm{K}_{2} \mathrm{CO}_{3}-\mathrm{SiO}_{2}$.

\begin{tabular}{cc}
\hline Samples & Activation Energy $\left(E_{a}\right)(e V)$ \\
\hline PKS0 & $5.51 \times 10^{-4}$ \\
PKS5 & $1.43 \times 10^{-4}$ \\
PKS10 & $1.30 \times 10^{-4}$ \\
PKS15 & $1.09 \times 10^{-4}$ \\
PKS20 & $1.55 \times 10^{-4}$ \\
PKS25 & $1.85 \times 10^{-4}$ \\
\hline
\end{tabular}

\subsubsection{Electrochemical Stability}

The electrochemical stability window (ESW) of the polymer electrolyte is a vital measure used in energy storage devices. The ESW of the PKS0 and of the highest conducting electrolyte (PKS15) at $5 \mathrm{mV} \mathrm{s}^{-1}$ scan rate is shown in Figure 13a,b. It was observed that the current remained constant with an increase in applied voltage until a definite limit $\left(\mathrm{V}_{\max }\right)$ was reached whereby the current suddenly increaseed rapidly for all electrolytes. This sudden current increment is linked to the decomposition of the polymer electrolyte [72,73]. It can be clearly observed that PKS15 electrolyte showed a wider electrochemical stability window of $3.35 \mathrm{~V}$ as compared to PKS0 at $2.7 \mathrm{~V}$. This could be attributed to the inclusion of silica particles that enhanced the electrochemical stability of the electrolyte. According to reported study, electrochemical stability may be influenced owing to the influence of the silica and the dielectric constant of the host polymer, which would give a higher concentration of charge carriers [74]. $\mathrm{SiO}_{2}$ is known to be an effective ingredient that increases the amorphous phase of the electrolyte, which is attributed to the creation of mobile defects as well as an increase in the flow of the material possibly at the interface region. Moreover, the degree of amorphosity that predominantly controls the ion conduction in the polymer matrix could be greatly enhanced by the incorporation of fillers [75]. Therefore, incorporation of $\mathrm{SiO}_{2}$ to the polymer electrolyte significantly increased the potential window of the synthesized electrolyte in this study. Similarly, addition of $\mathrm{SiO}_{2}$ is known to increase the anodic stability of the electrolytes [76].
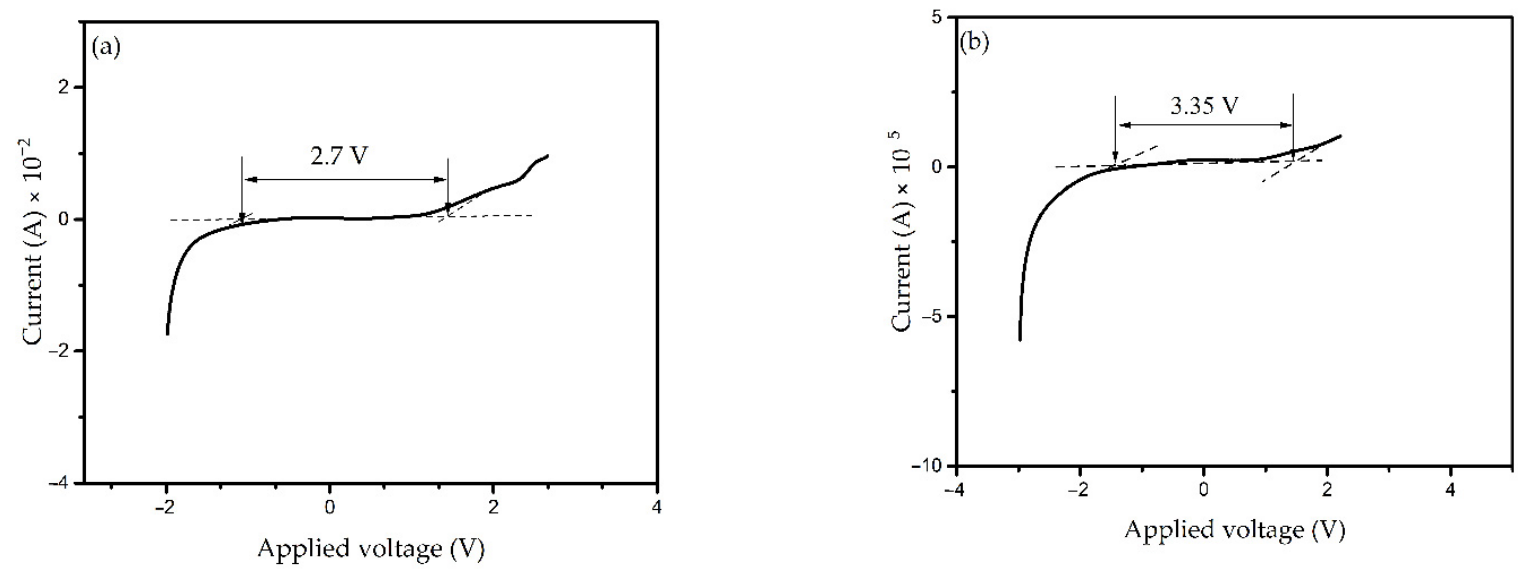

Figure 13. Linear sweep voltammetry (LSV) plots of the synthesized CPE (a) PKS0 and (b) PKS15 composites. 
Based on this study, the PVA- $\mathrm{K}_{2} \mathrm{CO}_{3}-\mathrm{SiO}_{2}$ system is electrochemically stable up to $3.35 \mathrm{~V}$, which is sufficient to allow safer application in next generation electrochemical devices. The result achieved in this study is higher than the minimum recommended standard electrochemical window $(1.7 \mathrm{~V})$ of an electrolyte material for EDLC applications of other studies earlier reported [77-79]. Therefore, the result demonstrates that the electrolyte synthesized and characterized in this study is suitable for fabrication in electrochemical devices.

\section{Conclusions}

In this study, various amounts of $\mathrm{SiO}_{2}$ particles as filler were incorporated into the non-filler PVA- $\mathrm{K}_{2} \mathrm{CO}_{3}$ composites to prepare composite polymer electrolytes (CPEs) with improved structural properties, ion transport mechanism, ionic conductivity, and potential window. The effect of $\mathrm{SiO}_{2}$ on the physical properties and ionic conductivity of PVA$\mathrm{K}_{2} \mathrm{CO}_{3}$ composite was clearly noticeable. FESEM and DSC studies indicated that the increase in amorphous phase was relatively high after incorporation of filler (plasticization). This is due to the effect of $\mathrm{SiO}_{2}$ particles, which relaxed the backbone of the polymer and hence yielded bendable and stretchable polymer backbone that aided in stimulating ionic movement in the polymer matrix. The optimum electrochemical performance was exhibited by PKS15 (15 wt.\% $\mathrm{SiO}_{2}$ ) with an optimum ionic conductivity of $7.86 \times 10^{-3} \mathrm{mScm}^{-1}$ at $373.15 \mathrm{~K}$ and a potential window of $3.35 \mathrm{~V}$. The temperature-conductivity relationship was found to follow Arrhenius equation. The results obtained show that the use of $\mathrm{SiO}_{2}$ to plasticized PVA- $\mathrm{K}_{2} \mathrm{CO}_{3}$ electrolyte has a better prospective for application in portable and bendable next generation electrochemical devices.

Author Contributions: Conceptualization, B.A.A. and J.O.D.; methodology, B.A.A., J.O.D., Y.A.-H., and M.F.B.A.S.; validation, J.O.D., Y.A.-H., M.F.B.A.S., and O.A.; formal analysis, B.A.A., J.O.D., Y.A.-H., and M.F.B.A.S.; investigation, B.A.A., F.U., and A.A.A.; resources, J.O.D., M.F.B.A.S., O.A., and K.H.I.; writing—original draft preparation, B.A.A.; writing—review and editing, J.O.D., M.F.B.A.S., O.A.; and K.H.I.; visualization, B.A.A., F.U., and A.A.A.; supervision, J.O.D., M.F.B.A.S., O.A., and K.H.I.; funding acquisition, J.O.D., Y.A.-H., E.M.M., O.A., K.H.I., and N.A.-H. All authors have read and agreed to the published version of the manuscript.

Funding: The Deanship of Scientific Research (DSR) at King Abdulaziz University, Jeddah, Saudi Arabia, funded this project, under grant no. (FP-69-42).

Data Availability Statement: The data presented in this study are available on request from the corresponding author. The data are not publicly available due to privacy.

Acknowledgments: The authors would like to thank the Deanship of Scientific Research (DSR) at King Abdulaziz University, Jeddah, Saudi Arabia, for funding this project and Universiti Teknologi PETRONAS, Malaysia, for providing research facilities and graduate assistantship. The authors would also acknowledge the supports of Physics Department, College of Science, Imam Mohammad Ibn Saud Islamic University (IMSIU), P.O. Box 5701, Riyadh 11432, Saudi Arabia.

Conflicts of Interest: The authors declare no conflict of interest.

\section{References}

1. Xiong, G.; Meng, C.; Reifenberger, R.G.; Irazoqui, P.P.; Fisher, T.S. A Review of Graphene-Based Electrochemical Microsupercapacitors. Electroanalysis 2014, 26, 30-51. [CrossRef]

2. Mun, Y.; Jo, C.; Hyeon, T.; Lee, J.; Ha, K.-S.; Jun, K.-W.; Lee, S.-H.; Hong, S.W.; Lee, H.I.; Yoon, S.; et al. Simple synthesis of hierarchically structured partially graphitized carbon by emulsion/block-copolymer co-template method for high power supercapacitors. Carbon 2013, 64, 391-402. [CrossRef]

3. Jin, Z.; Yan, X.; Yu, Y.; Zhao, G. Sustainable activated carbon fibers from liquefied wood with controllable porosity for highperformance supercapacitors. J. Mater. Chem. A 2014, 2, 11706-11715. [CrossRef]

4. Zhong, C.; Deng, Y.; Hu, W.; Qiao, J.; Zhang, L.; Zhang, J. A review of electrolyte materials and compositions for electrochemical supercapacitors. Chem. Soc. Rev. 2015, 44, 7484-7539. [CrossRef]

5. Naoi, K.; Ishimoto, S.; Miyamoto, J.-I.; Naoi, W. Second generation 'nanohybrid supercapacitor': Evolution of capacitive energy storage devices. Energy Environ. Sci. 2012, 5, 9363-9373. [CrossRef]

6. Li, Y.; Wong, K.W.; Ng, K.M. Ionic liquid decorated mesoporous silica nanoparticles: A new high-performance hybrid electrolyte for lithium batteries. Chem. Commun. 2016, 52, 4369-4372. [CrossRef] 
7. Polu, A.R.; Kumar, R. Preparation and characterization of pva based solid polymer electrolytes for electrochemical cell applications. Chin. J. Polym. Sci. 2013, 31, 641-648. [CrossRef]

8. Wang, K.; Zhang, X.; Li, C.; Sun, X.; Meng, Q.; Ma, Y.; Wei, Z. Chemically Crosslinked Hydrogel Film Leads to Integrated Flexible Supercapacitors with Superior Performance. Adv. Mater. 2015, 27, 7451-7457. [CrossRef]

9. Hema, M.; Selvasekarapandian, S.; Arunkumar, D.; Sakunthala, A.; Nithya, H. FTIR, XRD and ac impedance spectroscopic study on PVA based polymer electrolyte doped with $\mathrm{NH} 4 \mathrm{X}(\mathrm{X}=\mathrm{Cl}, \mathrm{Br}, \mathrm{I})$. J. Non-Crystalline Solids 2009, 355, 84-90. [CrossRef]

10. Aziz, S.B.; Faraj, M.G.; Abdullah, O.G. Impedance Spectroscopy as a Novel Approach to Probe the Phase Transition and Microstructures Existing in CS: PEO Based Blend Electrolytes. Sci. Rep. 2018, 8, 1-14. [CrossRef]

11. Aziz, S.B.; Abdullah, O.G. Effect of PVA Blending on Structural and Ion Transport Properties of CS: AgNt-Based Polymer. Polymers 2017, 9, 622. [CrossRef] [PubMed]

12. Fan, L.; Wang, M.; Zhang, Z.; Qin, G.; Hu, X.; Chen, Q. Preparation and Characterization of PVA Alkaline Solid Polymer Electrolyte with Addition of Bamboo Charcoal. Materials 2018, 11, 679. [CrossRef] [PubMed]

13. Fic, K.; Lota, G.; Meller, M.; Frackowiak, E. Novel insight into neutral medium as electrolyte for high-voltage supercapacitors. Energy Environ. Sci. 2012, 5, 5842-5850. [CrossRef]

14. Brandt, A.; Pohlmann, S.; Varzi, A.; Balducci, A.; Passerini, S. Ionic liquids in supercapacitors. MRS Bull. 2013, 38, 554-559. [CrossRef]

15. Gao, Y. Graphene and Polymer Composites for Supercapacitor Applications: A Review. Nanoscale Res. Lett. 2017, 12, 1-17. [CrossRef] [PubMed]

16. $\mathrm{Hu}, \mathrm{X}$.; Chen, Y.; Hu, Z.; Li, Y.; Ling, Z. All-Solid-State Supercapacitors Based on a Carbon-Filled Porous/Dense/Porous Layered Ceramic Electrolyte. J. Electrochem. Soc. 2018, 165, A1269-A1274. [CrossRef]

17. Lee, K.H.; Lee, Y.G.; Park, J.K.; Seung, D.Y. Effect of silica on the electrochemical characteristics of the plasticized polymer electrolytes based on the P(AN-co-MMA) copolymer. Solid State Ion. 2000, 133, 257-263. [CrossRef]

18. Pandey, K.; Asthana, N.; Dwivedi, M.M.; Chaturvedi, S.K. Effect of Plasticizers on Structural and Dielectric Behaviour of [PEO + (NH4)2C4H8(COO)2] Polymer Electrolyte. J. Polym. 2013, 2013, 1-12. [CrossRef]

19. Shekibi, Y.; Pringle, J.M.; Sun, J.; Pas, S.J.; Rocher, N.M.; Clare, B.R.; Hill, A.J.; MacFarlane, D.R.; Forsyth, M. Lithium-functionalised silica nanoparticles for enhanced ionic conductivity in an organic ionic plastic crystal. J. Mater. Chem. 2010, 20, 338-344. [CrossRef]

20. Sharma, J.P.; Sekhon, S.S. Effect of plasticizer and fumed silica on ionic conductivity behaviour of proton conducting polymer electrolytes containing HPF6. Bull. Mater. Sci. 2013, 36, 629-634. [CrossRef]

21. Hu, J.; Wang, W.; Yu, R.; Guo, M.; He, C.; Peng, H.; Peng, H.; Xue, Z. Solid polymer electrolyte based on ionic bond or covalent bond functionalized silica nanoparticles. RSC Adv. 2017, 7, 54986-54994. [CrossRef]

22. Ketabi, S.; Lian, K. Effect of $\mathrm{SiO}_{2}$ on conductivity and structural properties of PEO-EMIHSO4 polymer electrolyte and enabled solid electrochemical capacitors. Electrochim. Acta 2013, 103, 174-178. [CrossRef]

23. Abdulkadir, B.A.; Dennis, J.O.; Shukur, M.F.B.A.; Nasef, M.M.E.; Usman, F. Preparation and characterization of gel polymer electrolyte based on PVA- $\mathrm{K}_{2} \mathrm{CO}_{3}$. Polym. Technol. Mater. 2020, 59, 1679-1697. [CrossRef]

24. Shukur, M.F.; Ithnin, R.; Sonsudin, F.; Yahya, R.; Ahmad, Z.; Kadir, M.F.Z. Conduction Mechanism and Dielectric Properties of Solid Biopolymer Electrolyte Incorporated with Silver Nitrate. Adv. Mater. Res. 2013, 701, 115-119. [CrossRef]

25. Yusof, Y.M.; Illias, H.A.; Shukur, M.F.; Kadir, M.F.Z. Characterization of starch-chitosan blend-based electrolyte doped with ammonium iodide for application in proton batteries. Ionics 2016, 23, 681-697. [CrossRef]

26. Garaga, M.N.; Aguilera, L.; Yaghini, N.; Matic, A.; Persson, M.; Martinelli, A. Achieving enhanced ionic mobility in nanoporous silica by controlled surface interactions. Phys. Chem. Chem. Phys. 2017, 19, 5727-5736. [CrossRef]

27. Dodda, J.M.; Bělský, P.; Chmelař, J.; Remiš, T.; Smolná, K.; Tomáš, M.; Kullová, L.; Kadlec, J. Comparative study of PVA/SiO 2 and $\mathrm{PVA} / \mathrm{SiO}_{2}$ /glutaraldehyde (GA) nanocomposite membranes prepared by single-step solution casting method. J. Mater. Sci. 2015, 50, 6477-6490. [CrossRef]

28. Liu, Y.; Lee, J.Y.; Hong, L. In situ preparation of poly (ethylene oxide)-SiO ${ }_{2}$ composite polymer electrolytes. J. Power Sources 2004, 129, 303-311. [CrossRef]

29. Liew, C.-W.; Ramesh, S.; Arof, A. A novel approach on ionic liquid-based poly(vinyl alcohol) proton conductive polymer electrolytes for fuel cell applications. Int. J. Hydrogen Energy 2014, 39, 2917-2928. [CrossRef]

30. Gouda, M.; Gouveia, W.; Afonso, M.; Šljukić, B.; El Essawy, N.; Nassr, A.; Santos, J.L.M. Poly(vinyl alcohol)-based crosslinked ternary polymer blend doped with sulfonated graphene oxide as a sustainable composite membrane for direct borohydride fuel cells. J. Power Sources 2019, 432, 92-101. [CrossRef]

31. Aziz, S.B.; Woo, T.J.; Kadir, M.; Ahmed, H.M. A conceptual review on polymer electrolytes and ion transport models. J. Sci. Adv. Mater. Devices 2018, 3, 1-17. [CrossRef]

32. Long, L.; Wang, S.; Xiao, M.; Meng, Y. Polymer electrolytes for lithium polymer batteries. J. Mater. Chem. A 2016, 4, 10038-10069. [CrossRef]

33. An, Q.; Li, F.; Ji, Y.; Chen, H. Influence of polyvinyl alcohol on the surface morphology, separation and anti-fouling performance of the composite polyamide nanofiltration membranes. J. Membr. Sci. 2011, 367, 158-165. [CrossRef]

34. Dolui, S.K. Synthesis and Characterisation of Polyvinyl alcohol (PVA)/Silica Hybrid Composites Derived through the Sol-Gel Method in Aqueous Medium: Effect of Acid Content, Silica Content and Viscosity of PVA on the Dispersion. J. Sol-Gel Sci. Technol. 2004, 29, 107-114. 
35. Rosi, M.; Iskandar, F.; Abdullah, M. Hydrogel-Polymer Electrolytes Based on Polyvinyl Alcohol and Hydroxyethylcellulose for Supercapacitor Applications. Int. J. Electrochem. Sci. 2014, 9, 4251-4256.

36. Chen, L.; Fu, J.; Lu, Q.; Shi, L.; Li, M.; Dong, L.; Xu, Y.; Jia, R. Cross-linked polymeric ionic liquids ion gel electrolytes by in situ radical polymerization. Chem. Eng. J. 2019, 378, 122245. [CrossRef]

37. Yup, J.; Kang, D.A.; Un, N.; Min, J.; Hak, J. Bicontinuously crosslinked polymer electrolyte membranes with high ion conductivity and mechanical strength. J. Memb. Sci. 2019, 589, 117250.

38. Na, R.; Lu, N.; Zhang, S.; Huo, G.; Yang, Y.; Zhang, C.; Mu, Y.; Luo, Y.; Wang, G. Facile synthesis of a high-performance, fire-retardant organic gel polymer electrolyte for flexible solid-state supercapacitors. Electrochim. Acta 2018, 290, 262-272. [CrossRef]

39. Nishihara, M.; Terayama, Y.; Haji, T.; Lyth, S.M.; Satokawa, S.; Matsumoto, H. Proton-conductive nano zeolite-PVA composite film as a new water-absorbing electrolyte for water electrolysis. Express Polym. Lett. 2018, 12, 256-264. [CrossRef]

40. Chang, J.; Lai, H.; Samarahan, K. Polyvinyl alcohol/silica/clay composites: Effect of clay on surface morphology and thermomechanical properties. J. Teknol. Sci. Eng. 2016, 78, 45-53. [CrossRef]

41. Sik, D.; Bum, H.; Won, J.; Lee, Y.M. Preparation and characterization of crosslinked $\mathrm{PVA} / \mathrm{SiO}_{2}$ hybrid membranes containing sulfonic acid groups for direct methanol fuel cell applications. J. Membr. Sci. 2004, 240, 37-48.

42. Choo, K.; Ching, Y.C.; Chuah, C.H.; Julai, S.; Liou, N.-S. Preparation and Characterization of Polyvinyl Alcohol-Chitosan Composite Films Reinforced with Cellulose Nanofiber. Materials 2016, 9, 644. [CrossRef] [PubMed]

43. Ming, J.; Yuan, C.; Zen, H.; Chen, C. Two step modification of poly (vinyl alcohol) by UV radiation with 2-hydroxy ethyl methacrylate and sol-gel process for the application of polymer electrolyte membrane. J. Membr. Sci. 2009, 341, 186-194.

44. Çavuş, S.; Durgun, E. Poly(vinyl alcohol) Based Polymer Gel Electrolytes: Investigation on Their Conductivity and Characterization. Acta Phys. Pol. A 2016, 129, 621-624. [CrossRef]

45. Hassanjani, A.; Abdollah, R.; Safura, O. Determination of degradation kinetics of polyvinyl alcohol/X-zeolite nanocomposite. J. Therm. Anal. Calorim. 2016, 10,1-10.

46. Kadir, M.F.Z.; Hamsan, M.H. Green electrolytes based on dextran-chitosan blend and the effect of NH4SCN as proton provider on the electrical response studies. Ionics 2018, 24, 2379-2398. [CrossRef]

47. Liew, C.-W.; Ramesh, S.; Arof, A. Good prospect of ionic liquid based-poly(vinyl alcohol) polymer electrolytes for supercapacitors with excellent electrical, electrochemical and thermal properties. Int. J. Hydrogen Energy 2014, 39, 2953-2963. [CrossRef]

48. Liew, C.-W.; Ramesh, S. Comparing Triflate and Hexafluorophosphate Anions of Ionic Liquids in Polymer Electrolytes for Supercapacitor Applications. Materials 2014, 7, 4019-4033. [CrossRef]

49. Muchakayala, R.; Song, S.; Wang, J.; Fan, Y.; Bengeppagari, M.; Chen, J.; Tan, M. Development and supercapacitor application of ionic liquid-incorporated gel polymer electrolyte films. J. Ind. Eng. Chem. 2018, 59, 79-89. [CrossRef]

50. Chodankar, N.R.; Dubal, D.P.; Lokhande, A.C.; Lokhande, C.D. Ionically conducting PVA-LiClO 4 gel electrolyte for high performance flexible solid state supercapacitors. J. Colloid Interface Sci. 2015, 460, 370-376. [CrossRef]

51. Mishra, K.; Garg, A.; Sharma, R.; Gautam, R.; Pundir, S.S. Effect of blending of PMMA on PVdF-HFP $+\mathrm{NaCF}_{3} \mathrm{SO}_{3}-\mathrm{EC}_{-} \mathrm{PC}$ gel polymer electrolyte. Mater. Today Proc. 2019, 12, 621-627. [CrossRef]

52. Jiang, Y.; Xu, J.-M.; Zhuang, Q.-C.; Jin, L.-Y.; Sun, S.-G. A novel PEO-based composite solid-state polymer electrolyte with methyl group-functionalized SBA-15 filler for rechargeable lithium batteries. J. Solid State Electrochem. 2008, 12, 353-361. [CrossRef]

53. Yusof, Y.M.; Majid, N.A.; Kasmani, R.M.; Illias, H.A.; Kadir, M.F.Z. The Effect of Plasticization on Conductivity and Other Properties of Starch/Chitosan Blend Biopolymer Electrolyte Incorporated with Ammonium Iodide. Mol. Cryst. Liq. Cryst. 2014, 603, 73-88. [CrossRef]

54. Scrosati, B.; Croce, F.; Persi, L. Impedance Spectroscopy Study of PEO-Based Nanocomposite Polymer Electrolytes. J. Electrochem. Soc. 2000, 147, 1718-1721. [CrossRef]

55. Wang, X.; Hao, X.; Xia, Y.; Liang, Y.; Xia, X.; Tu, J. A polyacrylonitrile (PAN)-based double-layer multifunctional gel polymer electrolyte for lithium-sulfur batteries. J. Membr. Sci. 2019, 582, 37-47. [CrossRef]

56. Ramesh, S.; Wen, L.C. Investigation on the effects of addition of $\mathrm{SiO}_{2}$ nanoparticles on ionic conductivity, FTIR, and thermal properties of nanocomposite $\mathrm{PMMA}-\mathrm{LiCF}_{3} \mathrm{SO}_{3}-\mathrm{SiO}_{2}$. Ionics 2010, 16, 255-262. [CrossRef]

57. Tron, A.; Nosenko, A.; Park, Y.D.; Mun, J. Enhanced ionic conductivity of the solid electrolyte for lithium-ion batteries. J. Solid State Chem. 2018, 258, 467-470. [CrossRef]

58. Reddy, M.J.; Kumar, J.S.; Rao, U.S.; Chu, P.P. Structural and ionic conductivity of PEO blend PEG solid polymer electrolyte. Solid State Ion. 2006, 177, 253-256. [CrossRef]

59. Yusof, Y.M.; Shukur, M.F.; Illias, H.A.; Kadir, M.F.Z. Conductivity and electrical properties of corn starch-chitosan blend biopolymer electrolyte incorporated with ammonium iodide. Phys. Scr. 2014, 89, 1-10. [CrossRef]

60. Shukur, M.F.; Yusof, Y.M.; Zawawi, S.M.M.; Illias, H.A.; Kadir, M.F.Z. Conductivity and transport studies of plasticized chitosanbased proton conducting biopolymer electrolytes. Phys. Scr. 2013, 157. [CrossRef]

61. Zhao, B.; Lu, X.; Wang, Q.; Yang, J.; Zhao, J.; Zhou, H. Enhancing the ionic conductivity in a composite polymer electrolyte with ceramic nanoparticles anchored to charged polymer brushes. Chin. Chem. Lett. 2020, 31, 831-835. [CrossRef]

62. Shukur, M.F.; Azmi, M.S.; Zawawi, S.M.M.; Majid, N.A.; Illias, H.A.; Kadir, M.F.Z. Conductivity studies of biopolymer electrolytes based on chitosan incorporated with NH4Br. Phys. Scr. 2013, 157. [CrossRef]

63. Shukur, M.; Ithnin, R.; Illias, H.; Kadir, M. Proton conducting polymer electrolyte based on plasticized chitosan-PEO blend and application in electrochemical devices. Opt. Mater. 2013, 35, 1834-1841. [CrossRef] 
64. Agrawal, R.C.; Mahipal, Y.K.; Ashrafi, R. Materials and ion transport property studies on hot-press casted solid polymer electrolyte membranes: [(1-x) PEO: $\mathrm{X} \mathrm{KIO}_{3}$ ]. Solid State Ion. 2011, 192, 6-8. [CrossRef]

65. Raj, C.J.; Varma, K.B.R. Synthesis and electrical properties of the $(\mathrm{PVA})_{0.7}\left(\mathrm{KI}_{0.3} \cdot \mathrm{xH}_{2} \mathrm{SO}_{4}(0 \leq \mathrm{x} \leq 5)\right.$ polymer electrolytes and their performance in a primary $\mathrm{Zn} / \mathrm{MnO}_{2}$ battery. Electrochim. Acta 2010, 56, 649-656. [CrossRef]

66. Aziz, S.B.; Abidin, Z.; Arof, A. Effect of silver nanoparticles on the DC conductivity in chitosan-silver triflate polymer electrolyte. Phys. B: Condens. Matter 2010, 405, 4429-4433. [CrossRef]

67. Kou, Z.; Miao, C.; Mei, P.; Zhang, Y.; Yan, X.; Jiang, Y.; Xiao, W. Enhancing the cycling stability of all-solid-state lithium-ion batteries assembled with $\mathrm{Li}_{1.3} \mathrm{Al}_{0.3} \mathrm{Ti}_{1.7}\left(\mathrm{PO}_{4}\right)_{3}$ solid electrolytes prepared from precursor solutions with appropriate $\mathrm{pH}$ values. Ceram. Int. 2020, 46, 9629-9636. [CrossRef]

68. Wang, Z.; Miao, C.; Xiao, W.; Zhang, Y.; Mei, P.; Yan, X.; Jiang, Y.; Tian, M. Effect of different contents of organic-inorganic hybrid particles poly(methyl methacrylate) $\mathrm{ZrO}_{2}$ on the properties of poly(vinylidene fluoride-hexafluoroprolene)-based composite gel polymer electrolytes. Electrochim. Acta 2018, 272, 127-134. [CrossRef]

69. Xiao, W.; Wang, Z.; Zhang, Y.; Fang, R.; Yuan, Z.; Miao, C.; Yan, X.; Jiang, Y. Enhanced performance of P(VDF-HFP)-based composite polymer electrolytes doped with organic-inorganic hybrid particles $\mathrm{PMMA}_{\mathrm{ZrO}}$ for lithium ion batteries. J. Power Sources 2018, 382, 128-134. [CrossRef]

70. Ramesh, S.; Liew, C.-W.; Ramesh, K. Evaluation and investigation on the effect of ionic liquid onto PMMA-PVC gel polymer blend electrolytes. J. Non-Cryst. Solids 2011, 357, 2132-2138. [CrossRef]

71. Wang, Z.; Kou, Z.; Miao, C.; Xiao, W. Improved performance all-solid-state electrolytes with high compacted density of monodispersed spherical $\mathrm{Li}_{1.3} \mathrm{Al}_{0.3} \mathrm{Ti}_{1.7}\left(\mathrm{PO}_{4}\right)_{3}$ particles. Ceram. Int. 2019, 45, 14469-14473. [CrossRef]

72. Aziz, S.B.; Hamsan, M.H.; Abdullah, R.M.; Kadir, M.F.Z. A Promising Polymer Blend Electrolytes Based on Chitosan: Methyl Cellulose for EDLC Application with High Specific Capacitance and Energy Density. Mollecules 2019, 24, 2503. [CrossRef] [PubMed]

73. Noor, N.A.M.; Isa, M.I.N. Investigation on transport and thermal studies of solid polymer electrolyte based on carboxymethyl cellulose doped ammonium thiocyanate for potential application in electrochemical devices. Int. J. Hydrogen Energy 2019, 44, 8298-8306. [CrossRef]

74. Shukur, M.F.; Kadir, M.F.Z. Hydrogen ion conducting starch-chitosan blend based electrolyte for application in electrochemical devices. Electrochim. Acta 2015, 158, 152-165. [CrossRef]

75. Tan, X.; Wu, Y.; Tang, W.; Song, S.; Yao, J.; Wen, Z.; Lu, L.; Savilov, S.V.; Hu, N.; Molenda, J. Preparation of Nanocomposite Polymer Electrolyte via In Situ Synthesis of $\mathrm{SiO}_{2}$ Nanoparticles in PEO. Nanomaterials 2020, 10, 157. [CrossRef]

76. Xu, Z.; Yang, J.; Li, H.; Nuli, Y.; Wang, J. Electrolytes for advanced lithium ion batteries using silicon-based anodes. J. Mater. Chem. A 2019, 7, 9432-9446. [CrossRef]

77. Arof, A.K.; Kufian, M.Z.; Syukur, M.F.; Aziz, M.F.; Abdelrahman, A.E.; Majid, S.R. Electrical double layer capacitor using poly(methyl methacrylate) $-\mathrm{C}_{4} \mathrm{BO}_{8} \mathrm{Li}$ gel polymer electrolyte and carbonaceous material from shells of mata kucing (Dimocarpus longan) fruit. Electrochim. Acta 2012, 74, 39-45. [CrossRef]

78. Shuhaimi, N.E.A.; Majid, S.R.; Arof, A.K.; Shuhaimi, N.E.A.; Majid, S.R.; Arof, A.K. On complexation between methyl cellulose and ammonium nitrate on complexation between methyl cellulose and ammonium nitrate. Mater. Res. Innov. 2016, 13, 239-242. [CrossRef]

79. Samsudin, A.S.; Lai, H.M.; Isa, M.I.N. Biopolymer Materials Based Carboxymethyl Cellulose as a Proton Conducting Biopolymer Electrolyte for Application in Rechargeable Proton Battery. Electrochim. Acta 2014, 129, 1-13. [CrossRef] 